\title{
Archimedes and the Angel: Phantom Paths from Problems to Equations
}

Fabio Acerbi CNRS, UMR 8163 'Savoirs, textes, langage', Lille fabio.acerbi@wanadoo.fr

\section{Introduction}

This paper is a critical review of Reviel Netz' The Transformation of Mathematics in the Early Mediterranean World. ${ }^{1}$ Its aim is to show that Netz' methods of inquiry are too often unsatisfactory and to argue briefly for a substantially different interpretation of the evidence which he adduces. These two aims are pursued in parallel throughout the review and can hardly be disjoined. The review is uncommonly long and uncommonly direct, at times perhaps even a trifle vehement, in criticizing the methods and conclusions displayed in the book. There are two reasons for this. First, the transformation of Academic scholarship into a branch of the editorial business and, very recently, into an expanding division of the media-driven star-system, has dramatically reduced the time left to study primary sources, to get properly informed of works by other scholars, ${ }^{2}$ and even just to read more than once what was written as a first draft. Second, at the same time, it is increasingly difficult to find serious reviews. Though the number of reviews and book-notices is exploding, it is clear that most reviews are written just to get a copy of an otherwise too expensive book. At any rate, the current policy is to keep sharp criticisms, if any, hidden under a seemingly gentle stylistic surface.

The present paper is organized as follows. In the first section, I present Archimedes' problem; in the next, I report the contents

1 R. Netz, The Transformation of Mathematics in the Early Mediterranean World: From Problems to Equations. Cambridge: Cambridge University Press, 2004. Pp. ix + 198 (20 figures). ISBN 0-521-82996-8. Cloth £50.00, \$70.00.

2 See the lamentatio of the 85-year old P. O. Kristeller [1996, 567-583] for a lost way to scholarship in his 1990 Charles Homer Haskins lecture 'A Life of Learning'.

(C) 2005 Institute for Research in Classical Philosophy and Science All rights reserved

ISSN 1549-4497 (online) ISSN $1549-4470$ (print) ISSN 1549-4489 (CD-ROM) 
and aims of Netz' book. The third section introduces some general remarks on the book. Then, a very detailed analysis of Netz' arguments is expounded in the fourth and fifth sections; it is here that I adduce new evidence bearing on the main theme of the book. The closing parts of the fifth section contain, in very rough outline, an alternative assessment of all the evidence. (A warning to the reader: these last two sections often require having Netz' book at hand.) In the final section, I discuss some methodological issues.

\section{Archimedes' problem}

The book studies the transformation from Greek to Arabic mathematics of a very particular problem - we shall call it the original problem - that was left unsolved in Archimedes' De sphaera et cylindro 2.4, which proposes 'to cut a given sphere so that its segments have to each other a given ratio'. This problem is reduced so that one is required 'to cut a given $<$ straight line $>\Delta Z$ at $X$ and to bring about that as $X Z$ is to a given $<$ straight line $>$, so the given $<$ surface $>$ is to the $<$ square $>$ on $\Delta X^{\prime} .{ }^{3}$ We shall call this the unconstrained problem. In this form, the problem is not always solvable;

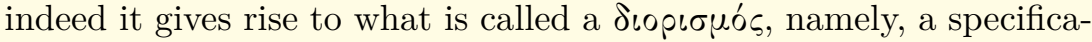
tion of the conditions of existence of the solution. If the constraints implied by the $\delta$ เopı $\sigma$ ós are embodied in the problem, then the problem is, of course, always solvable. The constrained problem is 'given two straight lines $B \Delta, B Z$ where $B \Delta$ is double of $B Z$ and $<$ given $>$ a point $\Theta$ on $B Z$, to cut $\Delta B$ at $X$ and to bring about that as the $<$ square $>$ on $B \Delta$ is to the one on $\Delta X, X Z$ is to $Z \Theta^{\prime}$ [cf. 14-15]. ${ }^{4}$ To cut the sphere, Archimedes takes the two problems as solved and promises that 'both of them will be analyzed and synthesized at the end' [Heiberg 1910-1915, 1.192.5-6]. No such appendix has been found in any surviving manuscript of De sph. et cyl. It was clearly unavailable to Dionysodorus and Diocles (both near contemporaries of Apollonius) who invented alternative approaches to the primary

3 Heiberg 1910-1915, 1.190.22-25. I have skipped the two expressions rightly bracketed by Heiberg. Translations are mine unless otherwise stated.

4 Heiberg 1910-1915, 1.192.1-5. $B$ is therefore a well-defined point on the basic line $\Delta Z$ of the unconstrained problem. The differences between the three problems are somewhat hidden in Netz' treatment, who conflates them to represent 'the Archimedean problem'. Greater care was in order. 
construction, and it remained missing up to the time when Eutocius (sixth century AD) wrote his commentary on the Archimedean treatise.

Indeed, it is with a real coup de théâtre ${ }^{5}$ that Eutocius claims, while commenting on De sph. et cyl.2.4, that he found Archimedes' solution 'in a certain old roll'. ${ }^{6}$ The copy, Eutocius writes, was marred with errors both in the text and in the diagrams but was still recognizable because the text preserved in part the 'beloved Doric dialect'. ${ }^{7}$ Eutocius goes on to propose Archimedes' solution as recovered from the 'old roll'. The commentator reports in succession Archimedes' analysis of the unconstrained problem, the synthesis of the same, and

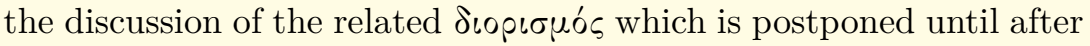
the synthesis. ${ }^{8}$ Further expansions of the proof by Eutocius follow. ${ }^{9}$ (Apparently, no solution of the constrained problem was contained in the putatively recovered appendix.) After that, Eutocius reports the alternative solution by Dionysodorus, ${ }^{10}$ who was not able to attack

5 Recall that the commentary on De sph. et cyl. is Eutocius' first work as a commentator, and that he presents it to his teacher Ammonius for judgment.

6 Usually translated 'book'. If the book was really as old as Eutocius claims, we can safely assume that it was a roll. That Eutocius writes on codices and consults them also when drawing from others' commentaries is clear from his references to writing his notes in the margins: see his commentaries to Apollonius' Conica [e.g., at Heiberg 1891-1893, 2.176.19-22 and 2.354.7-8].

7 Heiberg 1910-1915, 3.130.29-132.6. The extant text of De sph. et cyl. bears no traces of Doric dialect.

8 Heiberg 1910-1915, 3.132.19-136.13, 3.136.14-140.20, 3.140.21-146.28, respectively. Heiberg regarded the whole of 3.148.1-27 as Eutocius' addition

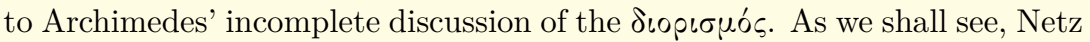
places the beginning of the addition earlier at 3.144.31.

9 Eutocius turns his attention to the relationships between the two forms of the reduced problem. He first shows that the constrained problem comes

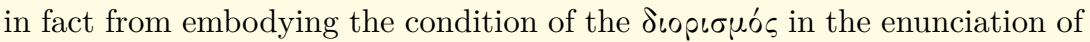
the unconstrained one [3.150.1-22]. Second, he puts emphasis on the fact that two points actually solve the problem, whenever this is solvable; but that only one of them effects the original construction and is in fact always contained in line $\Delta B[3.150 .23-152.14]$.

10 Heiberg 1910-1915, 3.152.27-160.2. A part of the proof is postponed as a lemma [3.158.13-160.2]. Dionysodorus' solution is not framed in the format of analysis and synthesis. 
the problems left unsolved by Archimedes ${ }^{11}$ and found an alternative way of solving the main problem directly. Eutocius then expounds the solution proposed by Diocles, who reduced the construction in a simpler way than Archimedes did and solved the problem resulting from this reduction (which is slightly different from Archimedes') through analysis and synthesis. ${ }^{12}$ Of the latter problem, Eutocius presents both the analysis and the synthesis, while the analogous text preserved in the Arabic tradition of On Burning Mirrors leaves out the synthesis on the grounds that it is 'clear'. ${ }^{13}$ This rather complex state of affairs constitutes the Greek evidence that Netz deals with in his book.

\section{Contents and aims of Netz' book}

After introducing the original problem, the first chapter ('The problem in the world of Archimedes') presents in succession Archimedes' synthesis and a part of the corresponding analysis [section 1.2] (we will say more below on this choice), the core of Dionysodorus' solution [1.4] - apart from a lemma which Netz judges irrelevant, though it is actually not so - and Diocles' reduction and his analysis of the reduced problem [1.5]. These sections consist mainly of translations and very detailed paraphrases of the several Greek texts. Two further sections $[1.3,1.6]$ underline the geometrical nature of Archimedes' problem as opposed to treating it as a search for solutions of a cubic equation. ${ }^{14}$ In these sections, we also find a characterization of the ideology of Greek geometers, who worked in a social context where

11 Eutocius points out this fact twice: see Heiberg 1910-1915, 3.130.19-22 and 3.152.16-21.

12 Heiberg 1910-1915, 3.160.3-162.16 (presentation of the construction and reduction), 3.162.17-168.25 (analysis), 3.168.26-174.4 (synthesis), 3.174.5176.5 (construction of cutting the sphere).

13 Editions in Toomer 1976, 77-87 and Rashed 2000, 119-125.

14 Netz [25-26] takes as representative of the latter interpretation a nonsensical patchwork of sentences that results from his cut-and-paste adaptation of Heath's three-page account of Archimedes' solution [Heath 1921, 43-45]. Using such a method, one might as well take the seven-line sentence on pages 91-92 of Netz' book (four of which are equations) as representative of his reading of the limits of solvability. 
agonism and self-promotion were the norm, ${ }^{15}$ that relies on the concept of 'aura' in W. Benjamin's sense:

the ancient author aimed at providing his work with an aurawith a sense of uniqueness that defies subsumption under any general heading. [59]

The second chapter ('From Archimedes to Eutocius') deals with the transformation and appropriation of Archimedes' solution by Eutocius. In sections 2.1 and 2.2, the Archimedean discussion of the limits of solvability is first presented, followed by a detailed analysis of what is originally Archimedean and what is Eutocius' addition. (Recall that the entire text is contained solely in Eutocius' commentary). Netz argues that the addition starts one full page before the line which Heiberg proposed in his edition. The strictly geometrical character of Archimedes' proof is then pointed out in section 2.3. Eutocius' contribution, which amounts to adding a missing case to the Archimedean proof and to commenting thereon, is analyzed in section 2.4 and declared to be original in two respects:

First, [Eutocius] describes the systematic relation holding in the line: the symmetry around the point E. Second, he has an explicit concept of a functional relation between mathematical objects. [94]

a claim that can hold true only if Netz is right to displace the beginning of Eutocius' addition as he has. ${ }^{16}$

Section 2.5 is probably the core of the book. Here we find a very detailed discussion of a particular expression denoting a solid as 'a surface epi line'. The expression comes from the analysis of the unconstrained problem in the following way. The requirement of cutting $\Delta Z$ at $X$ entails considering, for a given point $\Sigma$ on $\Delta Z$,

15 The obvious reference is to Lloyd 1996, cited once in Netz' book but not for this reason! Netz carefully takes his examples from Hellenistic mathematics. The explanation, however, does not work for every period of Greek mathematics, as is shown, e.g., by the Eutocian list of solutions of the problem of finding two mean proportionals between given lines, several of which are almost identical. Such are the proofs of Hero, Philo, and Apollonius, as well as those of Diocles and Pappus. The whole report is in Heiberg 1910-1915, 2.54.27-106.24. The hypothesis that later mathematicians were unaware of their predecessors' solutions is patently untenable.

16 These two points of originality are related in the following way: 
the solids whose base is the square on $\Delta \Sigma$ and whose height is $\Sigma Z$. These are shown to be equal to a solid built from a base surface and a height that are among the data of the problem; the sıoprouós comes exactly from the fact that there is a maximum to such $\Delta \Sigma Z$-solids at a point called $B$ such that $B Z$ is $1 / 3$ of $\Delta Z$. The constrained form of the problem takes this into account: the line $\Delta Z$ is already cut at the point $B$, and $X$ is sought on $\Delta B$ (thus, producing a solid less than the solid $\triangle B Z$ ) such that a certain proportion holds. Every such solid is denoted thereafter [cf. Heiberg 1910-1915, 3.136.7ff.] by the phrase 'surface epi line'. The epi expression lies, therefore, at the core of the whole proof. It is also to be found in De sph. et cyl. 2.8 aliter and in a lemma by Eutocius to it, as well as in several authors between Archimedes and Eutocius, even if it is not attested in 'mainstream' authors. ${ }^{17}$

The phrase 'surface epi line' may have both a geometric and an arithmetic connotation: on the one hand, a perpendicular is said to be epi a line or a plane; on the other, 'epi' denotes multiplication between numbers. ${ }^{18}$ The interest of such a register-crossing expression is best introduced in Netz' words: Archimedes employs it since 'he wishes to mark a piece of text, to endow it with its own distinctive aura. He therefore makes it different - and this difference leads on to the possibility of mathematical change' $[114] \cdot{ }^{19}$ In other terms, and considering also Eutocius' later appropriation:

But Eutocius also says how one point in the argument relates to another point in the argument [this is Netz' remark on the symmetry of the line], and therefore the relation between the points in the line becomes for him more like the relation between the points in the argument [this is Netz' concept of the functional relation between points]. [95]

17 The reader would have appreciated a list of the occurrences in the Archimedean corpus and in Eutocius' commentaries. As we shall see, Netz' census of the occurrences of the epi phrase in other Greek mathematicians is also at best partial.

18 In all instances, the form is $\varepsilon \pi i$ with the accusative.

19 On page 111, it is asserted that

all the occurrences of the special epi we study here appear in a continuous stretch of text. They appear either in (what is now) the penultimate proposition of Sphere and Cylinder II, or in the appendix to that book. 
But there is also a major way in which Archimedes' text, very surprisingly, makes a deliberate choice to deal with objects as if they were quantitative in nature. This choice, more than any other feature of Archimedes' text, points forwards towards a more algebraic understanding of the problem. Its later appropriation by Eutocius, in particular, would make Eutocius' text appear truly algebraic. [98]

All the above features of Eutocius' approach to mathematics find an explanation [section 2.6] within the category of deuteronomic text, introduced by Netz in a paper of $1998^{20}$ — note that the introduction of 'aura' is an addition to the argument of this paper. In a nutshell:

Archimedes and Diocles aimed at the individual aura; Eutocius aims at contextualization, which is the removal of aura. Hence, Eutocius' mathematics has concepts that are different from those of Archimedes and Diocles, and are different in a

The claim is obviously false, owing to the presence of the final proposition, unless a new notion of 'continuous' is admitted. Netz' tendentious specification '(what is now)' seems to point to arguments suggesting that the final proposition is spurious (no such arguments exist) and to the unwarranted assumption that there was in fact an Archimedean appendix: all of this forges the fiction of a 'continuous stretch of text'. There is more:

The second book of Sphere and Cylinder is a very complex combination of proportion theory $[$ sic] and solid geometry. Towards its end, it gets more and more complicated. The alternative proof for the penultimate proposition of the book has a unique structure, effectively a theorem for which only the analysis is given. Then the appendix may be the most complex piece of mathematics of the entire corpus. [111]

The last inference is ineffable, and no reader acquainted with the second book of De corporibus fluitantibus, for example, would agree with the resulting, totally subjective claim. Netz' goal is to make plausible the immediately following assertion: 'Our epi appears as a unique expression, perhaps intentionally employed to mark a unique context.' The reader should have already understood at this point where the subsequent discussion will lead. In the present book, the notion is presented this way:

We see then that a large part of intellectual activity in Late Antiquity was involved not with writing about things, but in writing about books. This is writing which is essentially dependent upon some previous writing — what I call a deuteronomic text. [121] 
well-defined way: Archimedes and Diocles perceive their objects as standing apart from each other, Eutocius sees them as continuously dependent upon each other. [125]

...the practice of a deuteronomic text-Eutocius' commentary on Archimedes - naturally gave rise to mathematical objects that are tied together by functional relations, and participate in equations. $[127]^{21}$

The third chapter ('From Archimedes to Khayyam') begins with a quick survey of 'the history of Archimedes' problem in the Arab world up to Khayyam' [129]. After an overview of the Arabic textual tradition of Archimedes' works and Eutocius' commentary, the contributions of al-Māhān̄i, Abu al Jūd, al-Khāzin, and Ibn al-Haytham are briefly presented, whereas the solution proposed by al-Qūhī is analyzed in greater detail. Section 3.2 offers some generalities about al-Khwārizmī's algebra. Khayyām's treatise Algebra is presented in section 3.3. The solution of Archimedes' construction appears again there, in a very disguised form, as one of the cases in a classification of cubic equations, 'A cube and a number equal a square', even if the solution is worked out in a geometrical setting by intersection of conic sections. Three principles underlie Khayyām's treatise; they are, as usual, best summarized in Netz' words:

The first was an inter-penetration of the introduction, and the treatise proper: the treatise was a direct continuation of the introduction, since the treatise was simultaneously, in algebra, and about algebra. The second was the strongly articulate, systematic nature of the treatise: it constantly arranges itself in various divisions and lists. Finally, we saw how the two features are connected through the principle of exhaustive lists. The interest of the treatise is in arranging claims - and objects - into systematic orders.... [154-155 $]^{22}$

Section 3.4 offers the translation of Khayyām's solution of the construction of cutting the sphere, and this is subsequently compared

21 Of course, from the perspective of a 'practice that naturally gives rise to [new] mathematical objects' [emphasis mine], it is difficult to explain why this does not happen to every commentator working on every text.

22 All italics in the quotations here and below are in the original, unless otherwise stated. 
with Archimedes' in section 3.5. Here Netz discusses, mainly with linguistic arguments, Khayyām's proof, which is shown to have a certain duality (in a sense, continuous with Archimedes himself) — conjuring non-geometrical possibilities, while manifesting a sustained geometrical conception of the problem. [161]

The main difference between the approaches taken by Archimedes and Khayyām lies in the obvious prominence that Khayyām gives to the study of cases and in his foregrounding of equalities over proportions, and in the fact that Archimedes does the opposite. Section 3.6 is devoted to discussing Khayyām's criticisms of Abu al Jūd's solution and to comparing Khayyām's polemical style with that of Dionysodorus and of Diocles. The section ends with a discussion of Sharraf al-Dīn al-Tūsı's 'Copernican revolution' of the ordering principle of Khayyām's classification: while the latter 'divided various equations into kinds, primarily, according to the geometrical tools they required' [179], the former looked at a systematization of the limits of solvability. In this way, Archimedes' original construction has finally become just an entry in a classification of equations. In section 3.7, such a difference, the main germs of which are in Khayyām's work, is shown to result 'from Khayyam's cultural practices which, like those of Eutocius, were deuteronomic - he was the author of texts essentially dependent upon previous texts' [129].

The aim of the book is to show that 'mathematics has a history' [1] by following step-by-step the transformation summarized above of Archimedes' problem into an equation. Two major historiographical turning points are under Netz' polemical focus. Sabetai Unguru's sharp criticisms [1975-1976, 1979] of the now abandoned treatment of some branches of Greek mathematics as 'geometrical algebra' are criticized in turn for having a-historically

led him away from studying the dynamics of the transformation from the ancient to the modern. Unguru's premise was that of a great divide separating ancient from modern thinking. The assumption of a great divide, in itself, is not conducive to the study of the dynamics leading from one side of the divide to the other. [4]

This is unfair, since it is undeniable that much of Unguru's later work fits very well his original program, namely, to understand ancient Greek mathematics in its own terms. The fons et origo of Unguru's 
premise is in Klein's Greek Mathematical Thought and the Origin of Algebra [1968]: ${ }^{23}$

Ancient mathematics (and science in general) was, according to Klein, based on a first-order ontology, modern mathematics (and science in general) is based on a second-order ontology. [5]

and they are separated by a great conceptual divide. Netz' goal is to refute the second horn of Klein's thesis while corroborating the first, ${ }^{24}$ by showing how second-order thought came out of the practice of commenting and systematizing earlier texts, specifically, the treatises of the great mathematicians of the first Hellenistic period whose works were raised to the status of canonical texts in late antiquity. ${ }^{25}$

\section{Scholarship}

Fascinating and deep theses, brilliant argumentation, an unmistakably flamboyant style, lucid and rhetorically very effective expositions of the difficult proofs presented, wide-ranging interpretative perspectives, and refined tools of analysis are the highlights of this very ambitious study. Yet the book is utterly disappointing. The point is not even whether Netz' approach should be labeled as history of mathematics, or whether, more likely, he is inventing a new genre, and whether this border-crossing will disturb hard-nosed and

23 This fundamental study is mis-cited by Netz in two ways: the 'Origin' in the title is everywhere written 'Origins'; and, though the reference in the bibliography is 'Klein, J. 1934-6/1968', the exact reference to the original study in German is nowhere to be found.

24 References to Klein's theses are scattered throughout the book.

25 In the author's own words:

To anticipate, my claim, in a nutshell, is that Late Antiquity and the Middle Ages were characterized by a culture of books-referringto-other-books (what I call a deuteronomic culture). This emphasized ordering and arranging previously given science: that is, it emphasized the systematic features of science. Early Greek mathematics, on the other hand, was more interested in the unique properties of isolated problems. The emphasis on the systematic led to an emphasis on the relations between concepts, giving rise to the features we associate with 'algebra'. [8] 
narrow-minded historians of mathematics as the present reviewer is. Netz' book simply raises serious problems of methods: it seems as though the traditional tools and careful approach of classical scholarship had to be wiped out in order to make the disruptive charge of the book manifest in full. Yet the shortcomings of the book can be described in wholly traditional terms: unfalsifiable conjectures about the aims and intentions of ancient mathematicians, unsatisfactory command and highly tendentious use of primary sources and of secondary literature, unwarranted resort to over-generalization and to modern mathematical concepts, taking conjectures as established facts about ancient mathematics - and treating the received texts and diagrams as if they were what their alleged author wrote in the first place (excepting, of course, the cases where the opposite stance supports the author's thesis).

The main thesis itself is a true masterpiece of interpretative insight; yet, I believe, it is simply not supported by the textual evidence adduced. The only conclusion one draws after reading Netz' book is that the Greek tradition is a dead end, and that Arabic mathematicians reconsidered the whole issue on entirely new grounds. Despite the author's efforts, there is no continuous trajectory from problems to equations, and Klein's thesis is in fact confirmed in its strongest form. The reader will look in vain for a discussion of possible influences on Arabic authors of Eutocius' alleged innovations. The only point of contact between the approaches of late Greek and Arabic mathematicians, their deuteronomic character, is by and large a historiographical artifact that is alleged to be supported by the very same evidence it was devised to explain. Moreover, Netz' willingness to prolong the bridge as far as Eutocius forces the author, as I shall show, to propose strained and at bottom misleading readings of the evidence itself. The attentive reader might have guessed the overall strategy already on page 16, where one reads, with undifferentiated reference to Archimedes' nest of problems: 'The trajectory, from problems to equations, is to a certain extent implied within the problem itself.' All of this is made to pass almost unperceived by virtue of the author's fascinating style, as he drives the reader away from where the real problems lie.

A minimal but significant example of Netz' masterly command of words is his use of the verb 're-deploy' [ix] to inform the reader that the book contains material coming from two studies previously 
published as journal articles. ${ }^{26}$ Such a practice is common among scholars, but should be kept within reasonable limits. In Netz' book, this 're-deploying' amounts to a massive verbatim reproduction of long stretches of text coming from those papers. Moreover, all translations from Greek in the book are also contained in the first volume of the translation of the works of Archimedes by the same author [Netz 2004]: Netz transfers them lock, stock, and barrel from the latter book to the one under review. The result is a detailed but fairly useless apparatus of references to propositions in the Elements,${ }^{27}$ a series of remarks of no subsequent use, and, most notably, a translation encumbered with a pedantic numbering of the steps of the proof. ${ }^{28}$ The latter device finds so infrequent use in the book that a more economical way to mark the handful of steps to be referred to would have been worth an afternoon's work. If one adds that the paraphrastic expositions of the several proofs translated take at least as many pages as the translations themselves, ${ }^{29}$ the outcome is

26 Netz 1999b, 2002a. Moreover, section 2.6 is an abrégé of Netz 1998.

27 Embarrassing consequences include, for example, presenting almost identical notes (to almost identical formulaic phrases): see 22n40, 31n47, $67 \mathrm{n} 4$.

28 Other drawbacks of the proposed translation include the orgiastic use of angular brackets: their presence can hardly be avoided in English in the case of understood words, a feature typical of mathematical prose style in ancient Greek, but it might be reduced to a reasonable minimum. For example, take the introduction of ' $<$ as $>$ ' in expressions such as 'cone having. . $Z A<$ as $>$

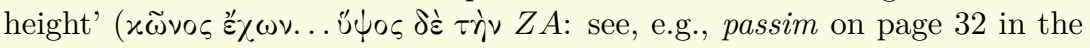
translation of Dionysodorus' text [Heiberg 1910-1915, 3.154-156]. This can

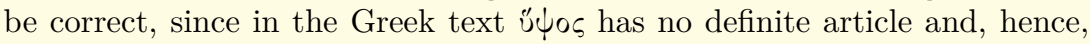
may be read as an appositive, the object being $\tau \dot{\eta} \nu ~ Z A$. But in English an idiomatic way to mark an appositive noun is to insert 'as' in front of it without the brackets. (But why not translate this more simply by 'cone having height $Z A^{\prime}$ '?) At any rate, here and elsewhere, Netz is transgressing his own principles of translation, since he should have translated $\tau \dot{\eta} v Z A$ regularly by 'the <line $>Z A$ '. Other problems with the translation will be pointed out in what follows, but this is rather a job for a reviewer of Netz 2004 [see, e.g., Sidoli 2005].

29 In fact, Netz' explanations of the several proofs translated attempt to clarify them by proposing a possible meta-analysis designed to reconstruct the original path of thought, very much in the style of Knorr 1986. Netz' analyses are more discursive, heuristic, and reader-friendly than Knorr's; but in both cases, the analyses are nothing but conjectures, and they tell more about the ingenuity of their proposers than about Greek mathematics. 
a book that adds nothing new to what the author had already said in previous publications. One might well wonder whether any real need was felt for such a book, beyond that of adding an item to the list of the author's academic publications.

I will illustrate the above points in what follows, as I try to uncover Netz' highly strategical presentation of the evidence and to indicate where a modicum of time devoted to the study of primary sources and secondary literature might have enriched the argumentative fabric of the book and helped to avoid some of its shortcomings. Most importantly, I will try to show that what appears to be the crucial step in the whole book is grounded on a very tendentious reading of the sources. I am not competent to judge the third chapter. As the journal Farhang is not easily accessible, I only list the pages in the book where Netz reproduces word for word his previous analysis of Khayyām's approach: pp. 145-160 [cf. Netz 2002a, 230-245], pp. 161-171 [Netz 2002a, 245-254], pp. 182-185 [Netz 2002a, 255-258]. The reader is invited to do a similar collation between chapter 2 of the present book and the corresponding paper in Archive for History of Exact Sciences [Netz 1999b] as an instructive exercise. ${ }^{30}$

\section{Minor characters}

Dionysodorus Netz' presentation of Dionysodorus' proof is misleading in that a completely artificial splitting of the proof is introduced at a step [Heiberg 1910-1915, 3.156.8-9] where a proportion identical with the one in Archimedes' unconstrained problem is reached. Such a step is presented as 'the goal of Dionysodorus' argument' [37], after which he, 'in effect, recapitulates Archimedes' argument as available to him, presenting it as his own' [38]. Neither claim is supported by the text: the step is not marked in any special way and what follows it in Dionysodorus' argument is fairly different from Archimedes', most notably through the introduction of an auxiliary cone.

30 Especially striking is a passage on page 77 produced by a masterful pasting of what in Netz 1999b, 28 were originally two separate sections: the title itself of the section is embodied in the text through the skillful introduction of a single clause! 
The equivalence of the auxiliary cone with the spherical segment is proved in a lemma which Netz does not report, and whose importance he clearly did not appreciate. ${ }^{31}$ Indeed, he underrates the importance of the condition $A Z=$ radius of the sphere [Heiberg 1910$1915,3.154 .5-6],{ }^{32}$ which is in fact a key assumption in the lemma: ${ }^{33}$ he states that 'no use is made [of the equality], inside the solution itself' [36]. But the lemma is an integral part of the solution; and it is stated as a lemma simply to make the proof not too cumbersome, a typical move among Greek geometers.

Another misleading feature of Netz' exposition, a feature that the reader encounters throughout the book, is the assumption that using a proportion implies an understanding that is quantitative, hence abstract, and hence algebraic. In the case of Dionysodorus, Netz intuits (this is the right word given the absence of any argument) 'from the way in which Dionysodorus makes his conic sections appear inside the proposition, that he conceives of them, in fact, in a more purely quantitative way than Archimedes did in his solution' [36]. Once this unwarranted and tendentious assumption is accepted - and I cannot see how the very short but still verbose argument on pages 36-37 can be thought to 'account for' the 'apparent paradox that Dionysodorus' basic setting is more geometrical, while his approach in the solution itself is more abstract'- such conclusions naturally follow as 'We begin to perceive a dialectical relation between the "geometrical" and the "abstract" (which we may even refer to as the "algebraic")' [37]. ${ }^{34}$ Yet, Dionysodorus' proof is nothing but the usual mixing of geometrical constructions and manipulations of equalities and proportions that is the distinctive feature of every non-elementary proof in Greek geometry. This whole nest of subtle misconceptions is devised to

31 In 32n61, the lemma is said 'not [to] touch on our main theme'; but this is true only in Netz' very partial reading of Dionysodorus' approach.

32 Another rash assertion is that '[Dionysodorus'] diagram was made to include an inert circle, $A \Pi B$, which does not participate in the solution' [36], while in fact the circle $A \Pi B$ represents the sphere to be cut and does indeed take part in the solution!

33 Most notably, such an assumption is what makes the application of De sph. et cyl. 2.2 possible at Heiberg 1910-1915, 3.158.17-19.

34 Cf. '[Dionysodorus' proof], where the conic sections and the very approach to the problem were rather quasi-algebraic' [53]. 
make Dionysodorus' proof fit the requirements of placing it in a preconceived interpretative scheme, one that looks at the 'algebraic' potentialities of Archimedes' problem. But the only honest answer to the question 'Where is [Dionysodorus's proof] in the trajectory leading from problems to equations?' [35] is 'Nowhere'-and in a strong sense, since the question itself is historiographically meaningful only in a teleological perspective: otherwise, the trajectory simply does not exist.

Diocles 'We do not know the chronological relation between Dionysodorus and Diocles' [39]. Of course, this is true in exact temporal terms; but Netz seems unaware of an interesting series of connections suggesting that Dionysodorus and Diocles were also chronological contemporaries and not only 'mathematical contemporaries' [39]. ${ }^{35}$ In the prefatory letter to Conica 2, which is addressed to Eudemus, Apollonius [Heiberg 1891-1893, 1.192.8-11] says: 'And Philonides the geometer, whom I introduced to you in Ephesus, if ever he is in Pergamum, acquaint him with it [scil. the second book] too.' Now,

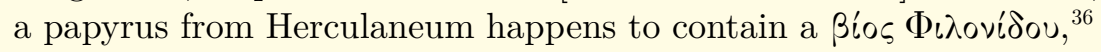
an Epicurean philosopher with strong mathematical bent. ${ }^{37}$ In this papyrus, we learn that Philonides had Eudemus and Dionysodorus of Caunos as teachers, that he collected and edited their lectures, and that he was acquainted with some Zenodorus. ${ }^{38}$ An obvious conjecture, still unchallenged since Crönert's first proposal, is that the latter two are the well-known mathematicians. On the other hand, in the prefatory letter to the extant version of On Burning Mirrors, Diocles refers to an astronomer who proposed that he find a surface concentrating the solar rays at one point. The Arabic name of the astronomer has been emended to a name compatible with Zenodorus in the original Greek by G. J. Toomer, though W. R. Knorr and R. Rashed read an otherwise unknown Hippodamus. As can be seen, the whole series of connections is by and large conjectural; but it fits well the extant evidence and in any event makes Netz' assertion rash.

35 See also Toomer 1976, 2.

36 See Crönert 1900 for the editio princeps. Gallo's new edition [1980] incorporates the detailed remarks offered in Capasso et alii 1976.

37 This and other testimonies contradict the widespread belief that the Epicureans had no interest in mathematics.

38 Fragments 7, 25, 32 and 31, 34, respectively. 
Diocles' Arabic text and its relationship with Eutocius' version are not discussed at all; and Netz' rejection of the synthesis proposed by Eutocius as an addition is given but a terse remark: 'this was in all likelihood Eutocius' own contribution (since, in the Arabic version, Diocles explicitly ignores the synthesis as trivial)' [44]. The only discussion of the issue is in a short paragraph [95], where we read that 'it is clear that the Arabic text may be closer, in some ways, to Diocles' text, than Eutocius' version is' and that 'it appears that Eutocius had interfered in Diocles' text in a way directly comparable with his interference in Archimedes' text.' ${ }^{39}$ The former sentence may well be true - and in such generic terms and with such modal qualifications it cannot be false - but it still calls for more argument. The Arabic Diocles is in fact already a translation of a Greek compilation: it is definitely not, as Netz seems to believe [39], the 'Arabic translation of Diocles' original treatise'. Consequently, the Arabic text of Diocles' solution should not be regarded as superior to the one we find in Eutocius on the sole basis of its being included in a work with the right title and author.

But even taking this for granted, let us look for a moment at Eutocius' interferences in Diocles' analysis. They are massive and radical: Diocles' introductory considerations and the reduction are almost identical, but the construction and the proof of the reduced problem are entirely rewritten and not just supplemented with additions: it is enough to compare steps 154-161 in Toomer's edition of the Arabic text with Heiberg 1910-1915, 2.164.4-19, where proportions are consistently replaced by equalities. Most notably, the whole proof in the Arabic text is formatted in the language of the 'givens', whereas Eutocius retains it at convenient places only. Therefore, the two versions should not be said to correspond 'very closely, though not exactly' [39n64], and the changes should not be described simply as 'Eutocius provid[ing], in his text, several very elementary arguments that are omitted in the Arabic version, besides including the synthesis of the problem' [95], as if the changes were only additions. Looking at the game the other way around, one is led to infer from this that Eutocius heavily reworked the text of the Archimedean appendix too. Since what will concern Netz are linguistic changes

39 There is a passing reference to a further discussion in $39 \mathrm{n} 64$. 
and not additions of whole portions of text, this would have serious consequences for the main thesis of the book.

As for Netz' analysis of the Greek proof, it is artificial to give prominence to the seemingly more complicated conditions in Diocles' problem (two proportions involving lines only instead of one proportion involving lines and areas): Netz speaks of 'the extreme artificiality of the conditions in Diocles' problem' [53: cf. 46], whose 'operating urge seems to be to distinguish the problem, as sharply as possible, from Archimedes' [46]. The artificiality is in the eyes of the interpreter. Very simply, Diocles had found a different way to solve the original problem - his way appears to be sufficiently different from Archimedes' and there was no reason not to mark it as such. In the same vein, it is tendentious to treat the addition to step 17 without mentioning the fact that the whole text has been heavily reworked so as to give this addition more prominence. Step 17 in Diocles' proof reads as follows in Netz' translation [42]: 'So through this, whenever $P$ falls between $A, Z$, then $\Sigma$ falls outside $H$, and vice versa' [Heiberg 1910-1915, 3.164.17-19]. The Arabic text is similar (the only similar step in a long stretch of text otherwise completely reworked), but without the 'vice versa'..$^{40} \mathrm{~A}$ minimal interpretation is that, when he came to step 17, Eutocius simply did his job, and did it well: when he perceived a missing step, a missing case, or an incomplete discussion, he supplied it. Eutocius did the same in

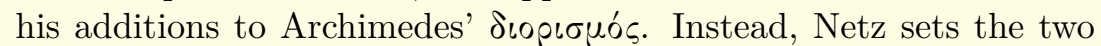
interventions in parallel to support his thesis that Eutocius, qua deuteronomic author, introduced germs of change into Archimedes' text:

the addition of the case changes the meaning of the argument: instead of a special observation on a special configuration, the text, transformed by Eutocius, sets out the constant relationships between possible configurations. [96]

All of this is at best unwarranted in Archimedes' case as well as in Diocles'.

Hero The presentation of the achievements of Hero is completely misleading, and relies on an imperfect knowledge of the Heronian

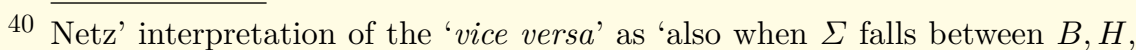
then $P$ falls outside $Z$ ' $[96]$ is wholly arbitrary, since this is not the only possibility. An exact converse would be 'when $\Sigma$ falls outside $H$, then $P$ falls between $A, Z$.' 
corpus. Netz takes Hero as the main source of 'a geometry organized around calculation and not... around proofs' [112]. Opposed to Hero is Archimedes, whose surviving texts are 'very clearly geared towards proof, and not towards calculation.... Rigor is the whole point of the discussion' [113]. This is but a partial image of the mathematical works of Hero. ${ }^{41}$ A cursory reading of the Metrica is enough to make one realize this fact: in addition to the calculations exemplifying the proposed formulas, rigorous proofs of the same formulas are provided in perfect 'Euclidean style'. In the same way, a number of full-fledged alternative proofs to Euclid's Elements are known to come from Hero's commentary, maybe the first one in the genre [see Vitrac 2004, esp. 30-34], and some of them, as the extant 3.12, found their way into the main Greek text. All of this makes meaningless Netz' claim that 'The Heronian register is in general defined relative to the Euclidean style. It is a variation on the Euclidean style' [113]. But there was no well-defined 'Heronian register', just as there was no 'Euclidean style' before Euclid became a canonical author in late antiquity. Referring to important studies by Jens Høyrup, ${ }^{42}$ Hero is made a champion of an approach rooted in 'oral calculation puzzles':

Hero, in particular, seems to employ even a language reminiscent of such calculation puzzles: we recall his treatment of geometrical relations in terms of multiplication, and Archimedes' deliberate exploitation of this tradition. [141]

One should bear in mind that Høyrup's researches are mainly, if not exclusively, focused on the Geometrica and that this work, ${ }^{43}$ although included in the Heronian corpus, is definitely apocryphal. Moreover, one cannot rightly speak of 'deliberate exploitation' of the tradition

41 The whole discussion on pages $113-114$ is vitiated by the embarrassing fact that Hero comes well after Archimedes, whereas Netz' reconstruction would have greatly benefited from the opposite. Netz remarkably allows: 'Not that Hero is a perfect antecedent [scil. of Archimedes]' [113].

42 And not 'Hoyrup' as we find throughout the book. Notice also that the paper cited by Netz does not contain any analysis of the Greek tradition apart from a short discussion of Elem. 2. A better reference would have been Høyrup 1997.

43 Note that the use of the singular is actually unwarranted, since the work is ' $\mathrm{a}$ modern conglomerate of two (indeed more) ancient conglomerates' [Høyrup 1997, 73]. 
by Archimedes: there is not the slightest information about when and where the tradition passed from the Ancient Near East to Greece. In the same vein, to assert after a half-page resumé of Høyrup's findings that 'In the Ancient Greek world, the two forms - literate geometry, and oral calculation puzzles - subsisted separately, ${ }^{44}$ with occasional contacts [... ' [141] is to state a dichotomy that is false in two fundamental respects. First, the two forms did not exhaust the ancient mathematical field, as Netz' formulation suggests: neither of the authors mentioned in the same page, Hero and Diophantus, exclusively practiced either of them, and neither the metrical tradition nor an-

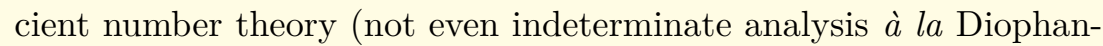
tus) should be defined simply as 'oral calculation puzzles'. Second, no mathematical tradition subsisted separately from the others, as is shown by the very same authors, and the contacts were more than simply occasional. In the following section, I will discuss Netz' use of the evidence for the epi phrase as it appears in Hero's Metrica.

The core of the argument

The main task of the present paper is to discuss the crucial issues

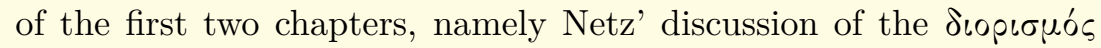
and the relevance of the epi phrase. I will argue that the textual evidence indicates that the epi expression was not in Archimedes' original texts; that Netz' presentation of this evidence is tendentiously incomplete; and that Eutocius introduces no change, since in fact the use of the expression in geometrical and mixed settings was a matter of routine well before him.

The extent of Eutocius' reworking of the appendix Eutocius expressly says that he rewrote the entire Archimedean tract. Netz believes the opposite: 'Eutocius promises to transcribe this text "as it has been written"' [72]. Netz is drawing primarily on Heiberg 19151910, 3.132.12, but there Eutocius only claims to have 'studied the text as it has been written'. In fact, Eutocius immediately explains that what he will do with the text is to 'write the ideas as far as possible in a language common and clear' [3.132.14-15]. The sentence is paraphrased by Netz [72], who goes beyond the text in making

44 The problem here lies in asserting the oral character of a tradition about which we are (of course) acquainted through written sources only. 
the references explicit and specific, as '[to] re-write the proof with modern terminology and in the dominant dialect', thereby excluding any serious reworking of the text. Netz' reference is to the fact, mentioned by Eutocius a few lines before, that the recovered text employed the Doric dialect and an obsolete terminology: exactly these features made Eutocius suspect that he had hit upon Archimedes' appendix [3.132.5-11]. Yet, the clause at 3.132.14-15 is preceded by a description of the defects of the recovered text which strongly suggests that Eutocius' rewriting went well beyond a few cosmetic changes: 'since we found $<$ the text $>$ difficult, because, as has been said, of the number of mistakes, after having stripped off the ideas one by one we write $<$ them $>$ as far as possible in a language common and clear' [3.132.12-15]. ${ }^{45}$ Maybe Netz was misled by his own earlier mistranslation of the clause at $3.132 .14-15:{ }^{46}$ 'We write [the content] down as far as possible, word-for-word (but in a language that is more widely used, and clearer)' [Netz 2004, 318]. The Greek

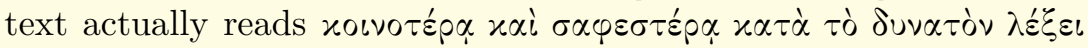

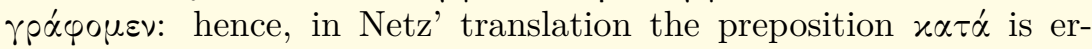
roneously distributed between $\delta \cup v \alpha \tau o ́ v$ and $\lambda \varepsilon^{\prime} \xi \varepsilon \iota$. His mistake may come from his reading $\varkappa \alpha \tau \dot{\alpha} \lambda \hat{\varepsilon}^{\prime} \xi_{\iota \nu}$ which does mean 'word-for-word'. ${ }^{47}$ On this crucial error rests Netz' belief that we may confidently read the text of the recovered appendix as faithfully Archimedean.

Eutocius gives us no examples of theorems by pre-Apollonian mathematicians for which he did not heavily rework the sources. As we have seen, the text of Diocles' solution is a first instance. Eutocius also asserts that he has 'corrected' Dionysodorus' solution of

45 A detailed mention of the poor status of the text in the 'old roll' was already made at 3.132.1-4: "we read theorems written there which were obscure in parts because of the errors and which were mistaken in a variety of ways about the diagrams.'

46 The right translation is provided in Decorps-Foulquier 2000, 73n52, for example, in the context of a very detailed analysis of Eutocius' editorial procedures. The book is cited once by Netz [18n20]; however, the reference is very generic, and, most importantly, it is in a note to the translation of the alleged Archimedean synthesis. Therefore, the reference belongs in the material that has been lifted from Netz 2004.

47 There is a well-known occurrence of this phrase in Simplicius' statement [Diels 1882, 60.27] that he will transcribe $\varkappa \alpha \tau \dot{\alpha} \lambda \boldsymbol{\varepsilon}^{\prime} \xi \iota$ Eudemus' report of Hippocrates' quadrature of lunules. 
Archimedes' original construction because 'it too' was marred with

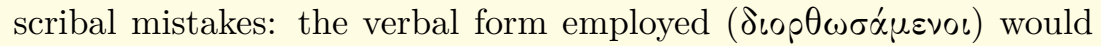
normally entail more than slight interventions [see Heiberg 1910$1915,3.152 .15-26$, esp. 152.22]. Other obvious cases in point are found among the several solutions of the problem of finding two mean proportionals which Eutocius offers in his long excursus in the commentary to De sph. et cyl.2.1: radical interventions can be detected, for instance, in the solutions by Diocles, Menaechmus, and Archytas apud Eudemus [Heiberg 1910-1915, 3.66.8-70.5, 78.13-84.7, 84.1288.2, resp.]. ${ }^{48}$ Eutocius also modifies extensively the Apollonian proof of the locus-theorem which he reports in his commentary to the Con$i c a$, as is clear from the Arabic sources. ${ }^{49}$

Eutocius' editorial principles are briefly expounded in his commentary to Apollonius' Conica [Heiberg 1891-1893, 2.176.17-22 and 354.5-7]. ${ }^{50}$ Most notably, in sending Anthemius the revised fourth book of the Conica, Eutocius writes that Anthemius will find that it 'is satisfying and clear for the readers, most notably in [his own] edition' [2.354.5-7]. Such exigencies of 'clarity', often referred to in his commentaries when editorial choices are to be justified, ${ }^{51}$ would naturally have induced Eutocius to rewrite the text of the 'old roll'; and this has to be taken as the most likely hypothesis, unless compelling evidence to the contrary is adduced. Several recent works have shown that Eutocius affected the very structure of the Apollonian treatise ${ }^{52}$ even if there has been no study yet of the possibility of his intrusions at a linguistic level. Partial results in this direction include, for example, the proposal that the exact references to theorems in Apollonius' Conica which are found in the commentary to De sph. et cyl.2.4 are in fact post-Eutocian additions, and that there was later editing of the Eutocian text of the Conica. ${ }^{53}$

48 See the analyses in Knorr 1989, esp. 81-87, 94-110, 225-245. This fundamental book is never cited by Netz.

49 Heiberg 1891-1893, 2.180.11-184.20, to be compared with the evidence presented in Hogendijk 1985, 213-218.

50 See Decorps-Foulquier 1998 and 2000, esp. 67-97.

51 See Decorps-Foulquier 1998.

52 One should add Knorr 1982 at least to the studies cited in the preceding notes.

53 See Decorps-Foulquier 2000, 82n92, 128-134. 
It is plain that, on these grounds, no inference can be drawn from lexical peculiarities of the Archimedean appendix. The safest assumption is that the language in which it is written is Eutocius' language. Of this crucial point, Netz offers a discussion that is entirely unsatisfactory: the argument takes less than one page and its outcome is the following assumption:

Other than this [scil. the terminology of conic sections] Greek mathematical terminology hardly changed through the centuries between Archimedes and Apollonius.... These three transformations - critical corrections, dialect translation, and terminological standardization - are all innocuous. [72]

But this is exactly what is to be proven, namely, that the presence of an extremely peculiar mathematical phrase in an alleged Archimedean text reported by Eutocius is not a consequence of Eutocius' reworking. The rest of the discussion, which extends as far as page 84, take this assumption as an acquired fact and proceeds to a remarkable attempt at 'distinguishing Archimedes from Eutocius' (as in the title of the section), i.e., to segregate which portions of the

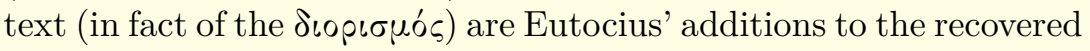
Archimedean appendix. Thus, Netz offers a black-and-white reconstruction: from a certain Heiberg-line onwards, there are Eutocius' additions, in particular, what will subsequently be called 'the second part of the proof' - see immediately below for an account of the relations between the two parts - before that line there is Archimedes' text of the lost appendix, affected only by trifling, cosmetic changes in the process of editing. Other interpretations are ruled out a priori and Netz even seems to regard more nuanced accounts as a product of 'philological paranoia' [76]. As is clear, the whole discussion is conducted in a tendentious way, since the reader is diverted from the real point, namely, whether there are conspicuous linguistic changes introduced by Eutocius in the text, to the secondary issues of whether the text recovered by Eutocius was really Archimedean or where Eu-

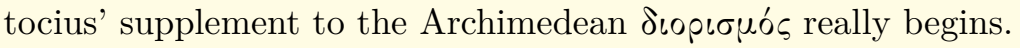

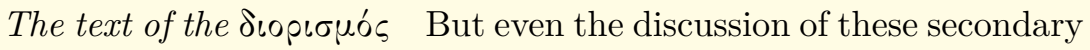
issues is in fact unsatisfactory. As a preliminary caveat, notice that the goal of sifting out Eutocius' additions (in Archimedes' as well as in Diocles' case) is undertaken in order to show that Eutocius had an explicit concept of a functional relation between objects [94: 


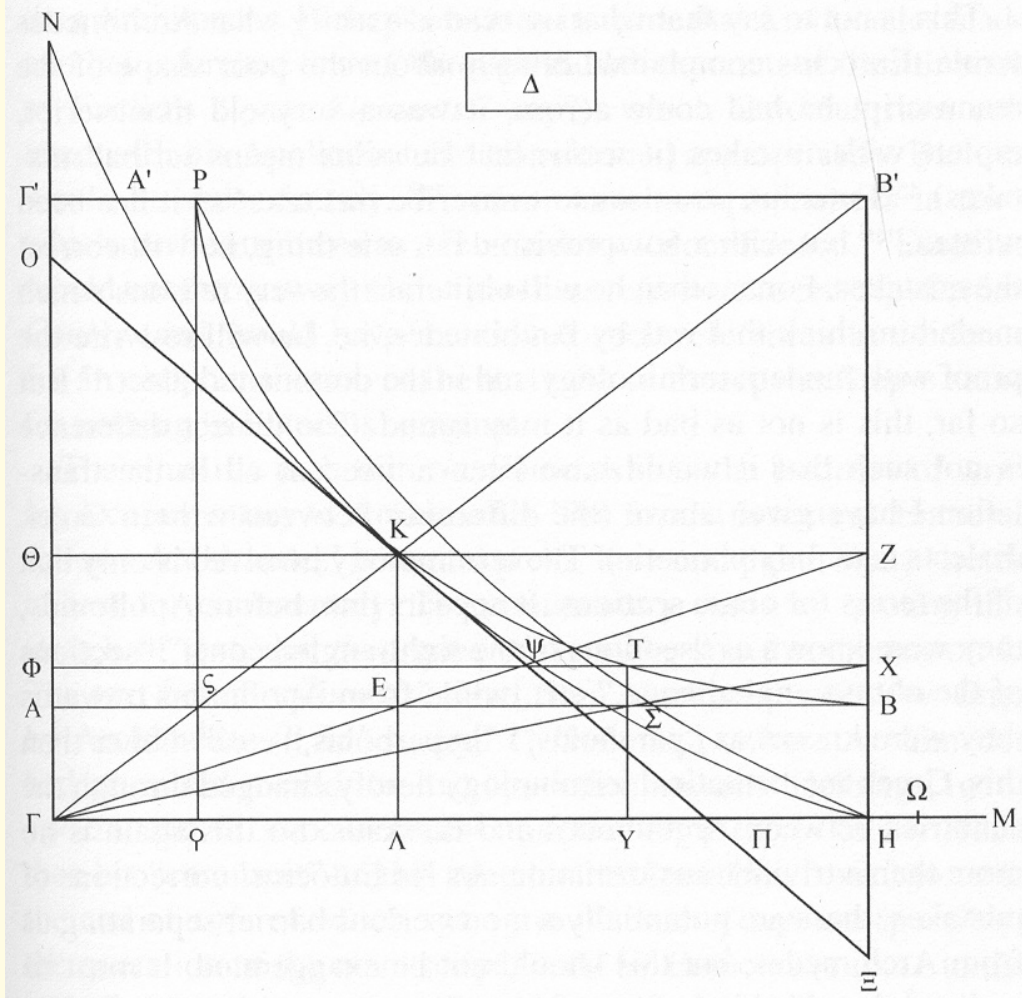

Figure 1. The diagram of the sıopıouós [71]

quoted on p. 172, above]. This is a side issue in relation to Netz' main thesis, the transition from problems to equations through the introduction of elements leading towards an algebraic approach. But it is strategically crucial in making more credible the general portrait of Eutocius as injecting germs of later mathematics.

The idea of a functional relation between points comes out

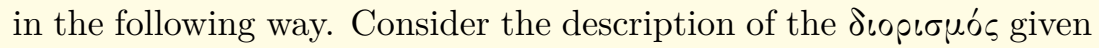
above. The first part of the $\delta$ เopıбuós proves that any $B \Sigma A$-solid is less than the $B E A$-solid when an arbitrary point $\Sigma$ is taken between $E$ and $B$; the second part shows that the same holds true even when the arbitrary point $\Sigma$ (now called $\zeta$ ) is taken between $E$ and $A$. (The reader must not be bewildered by the change in the lettering. It occurs in the Eutocian appendix too: the line to be cut 
is now $A B$, point $E$ is where the maximum is reached, $E B$ is the diameter of the sphere and $A E$ is equal to its radius, which means that $A E$ is $1 / 3$ of $A B .{ }^{54}$ ) Now, $\zeta$ is found by means of the very point $\Sigma$ already displayed in the first part of the proof. The trick is to set the $B \zeta A$-solid equal to the $B \Sigma A$-solid, even if this equality is a only a consequence of two other equalities stated in the text. ${ }^{55}$ Eutocius rec-

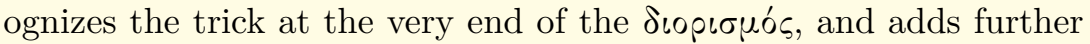
considerations [Heiberg 1910-1915, 3.148.7-27] which Netz takes to entail that Eutocius has an explicit concept of a functional relation between mathematical objects. I will provide further details below, but it is mandatory to discuss the textual issues first.

That Eutocius added the second part of the proof is very likely, simply because Archimedes was not interested, from the very outset, in what was going to happen between $A$ and $E: E B$ is the diameter of the sphere and the point useful for cutting the sphere itself must, therefore, fall between $E$ and $B$. As we have seen for Diocles, missing (and very often useless) cases and steps are exactly what a wise commentator supplies. The thesis is, therefore, highly plausible (even if, I repeat, its strategic character must be borne in mind); but the discussion [75-85] supporting the new location of the beginning of

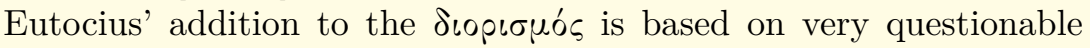
arguments. I will discuss each of them in succession.

Netz' first argument [76] is ex silentio and it is the only one of-

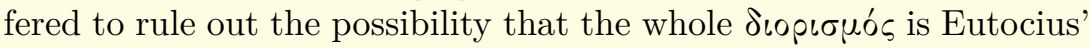
forgery: 'had [Eutocius] invented anything as original as [the $\delta \iota p \iota-$ $\left.\sigma \mu o_{s}\right]$ he would have been wild of pride... we would be certain to hear much more of this, had Eutocius been creative at such a scale.' This is plausible even if the inference is far from cogent, as Netz himself notes. Still there are other possibilities. In fact, it is odd that Eutocius dismisses the issue of authenticity in so few words: he alludes

54 In Netz' book, the correspondence between the different letterings has to be deduced from the texts alone; Netz offers his reader no explanation. The correspondence is $Z \rightarrow A, \Delta \rightarrow B, B \rightarrow E$.

55 Actually, the consequence is immediate: both the $B \varsigma A$-solid and the $B \Sigma A$ solid are equal to 'the <rectangle contained $>$ by $\varsigma H \Omega$ epi $\varsigma A$ '. This is proven and the statements of the equalities are in steps 35 and 52 [Heiberg 1910-1915, 3.144.25-26 and 3.146.19-20, resp.]. Eutocius simply states the equality, adding 'as is manifest from the preceding proofs' [Heiberg 19101915, 3.148.17-18]. 
only to the Doric dialect and to the archaic terminology for the conic sections. But Eutocius had already read Archimedes' De sph. et cyl. without Doric as his lemmata show; and the idea that one can date a text on the basis of its 'archaic' terminology for conic sections is a historiographical fiction perpetuated from the times of Eutocius at least. ${ }^{56} \mathrm{He}$ may well have had this as a firm belief, but we are not forced to share his convictions. Notice also that Eutocius' description of the 'old roll' appears to entail that the Archimedean text was not contained there as an appendix to the main treatise but as an isolated text, of course, without any indications of authorship. (It might also have been the only text contained in the roll, but more likely the roll was a miscellany). Moreover, the standards and means of a critique of authenticity had been in development since the times of the first Alexandrian scholars; and by the sixth century AD, a century of heated religious controversy, there were in hand some comparatively refined tools available to uncover forgeries ${ }^{57}$ One would, accordingly, have expected a more detailed discussion from Eutocius.

The second argument [77-81] is a detailed analysis of the presence in the diagram of a phantom parabola whose defining relations are set out in the first part of the proof, but which is identified and used only in the second part, in a passage already recognized as Eutocian by Heiberg himself [1910-1915, 3.148.7-10]. A first remark is

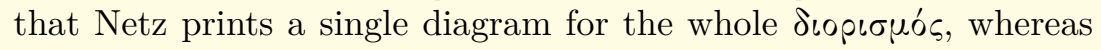
Heiberg has two. Heiberg chose to split the diagram into two for clarity's sake. ${ }^{58}$ Neither in the book under review nor in his earlier

56 The spreading of the Apollonian terminology was very likely far slower than usually believed. Most notably, one should explain away the several occurrences of archaic terminology in fragments from Geminus - e.g., in his optical fragment (see, e.g., pseudo-Hero, Definitiones 135.13 [Heiberg 1912, 108.1]) and in the classification of lines reported by Proclus [Friedlein 1873, 111.7-8] — and in the material collected in the pseudo-Heronian Def. n. 94 [Heiberg 1912, 60.1-5]. See also Toomer 1976, 9-10, on the presence of the 'archaic' designations of conic sections in Diocles' work. Other alleged instances of 'archaic' terminology have recently been recognized as historiographical fictions as well: on the use of complex expressions to denote points

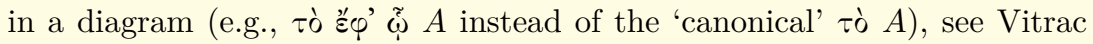
2002 , esp. $245-255$.

57 For an introductory assessment, see, e.g., Wilson 1996, $53 \mathrm{ff}$.

58 Heiberg 1910-1915, 3.142 in apparatu. 
translation [Netz 2004] is there any reference to this discrepancy. A second remark of greater importance is that there is no need to follow Netz in reading what he calls steps $\mathrm{v}$ and $\mathrm{b}^{\prime}$ as 'indirectly defin[ing] a parabola around the axis $Z H$, passing through $T, P \ldots$, ${ }^{59}$ which entails as a consequence that 'the diagram includes a meaningful line which is not mentioned by the text as we have it' [77]. ${ }^{60}$ The two steps may indeed be read as giving the definitional relation of a parabola passing through $T$ and $P$, respectively, and with latus rectum $H \Omega$; but this is not the role they play in the proof. Here they serve as intermediate steps in a long chain of equalities involving squares and rectangles. In fact, step $\mathrm{v}$ is necessary for achieving the first part of the proof and step $\mathrm{b}^{\prime}$ for achieving the second. As for the remark that the parabola is in the diagram from the very outset, this is naïve (had Eutocius to produce a multi-layered diagram?) The simple fact is that Eutocius was used to redrawing all diagrams and compressing all information contained in a proof into a single diagram, even if the proof had several cases. ${ }^{61}$ So, it is not surprising that the same

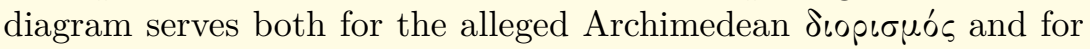
Eutocius' remarks immediately following it. It is not the case, then, that we are here facing a further example of Netz' tenet that 'it often happens that the specification of objects in Greek mathematics is left for the diagram, so that the textual specification is a subset of the

59 In Netz' translation [69-70], step v: 'So let the $<$ square $>$ on $T X$ come to be equal to the $<$ rectangle contained $>$ by $X H \Omega^{\prime}$ [Heiberg 1910-1915, 3.144.19-20];

step b': 'Let the <square> on $P B^{\prime}$ come to be equal to the $<$ rectangle contained > by $B^{\prime} H \Omega$ ' [Heiberg 1910-1915, 3.146.14-15].

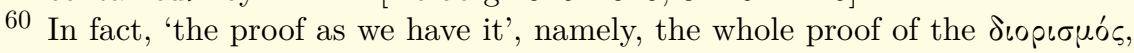
obviously contains the introduction of the parabola - unless one has already decided what belongs to Archimedes and what does not, that is, unless one takes for granted, as Netz does already in this second argument, exactly what one has set out to prove.

61 This is explained in detail in Decorps-Foulquier 1999; 2000, 94-97. The poor condition of the diagrams was pointed out by Eutocius in his initial description of the recovered appendix, as we have seen. 
diagrammatic specification' [78];62 and I do not see how it may be said that in the present instance 'the specification of the text and the specification of the diagram clash' [79]. There is no contradiction at all between text and diagram. ${ }^{63}$ But Netz assumes that there is and is then led to discuss the location in the proof of what he calls step $\mathrm{p}$, where point $P$, one of the points on the phantom parabola, ${ }^{64}$ is apparently first introduced as a further point on a hyperbola. The discussion is confused and fallacious.

In the first place, step p [Heiberg 1910-1915, 3.144.7-8] is translated as follows [68-69]: 'So let the hyperbola, produced, as towards $P$, be imagined as well.' This is not a good translation. It should read: 'So, let the hyperbola also be conceived as produced as far as $P .{ }^{165}$ The difference is crucial. The first translation might be the basis for asserting that " $\mathrm{t}$ ] he text of Step p seems to assume that the hyperbola of the diagram ends at $K$, and that there is a freefloating point $P$ indicating the location of the continuation of the hyperbola' [79]. (Recall once more that this single diagram is to

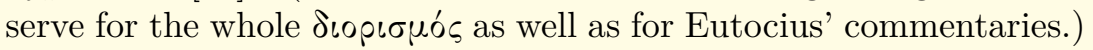
One might even infer that '[s] uch a free-floating point is in itself a bold innovation' [80], were it not for the fact that the point is firmly placed on the hyperbola. However, as is clear from the second and correct translation, the Greek text simply conveys the sense that one is invited to conceive the hyperbola produced as far as a convenient point, called $P$. Introducing points whose specification is provided later in the proof, a move that is standard in Greek mathematics ${ }^{66}$ is simply dictated by the reasonable aim of keeping the number of labeled points to a strict minimum.

62 Reference is made to Netz 1999a, chapter 1. This is a paradigmatic example of the author's eagerness to take his own interpretations as well-established facts. I completely disagree with the thesis of the chapter referred to, if not because the small sample of evidence there analyzed makes a general statement as the one just quoted unwarranted.

63 A little later on the same page, 'another clash between text and diagram' is discovered in step p, when a hyperbola is 'imagined' to be produced as far as a point called $P$. We will discuss this step presently.

${ }^{64}$ But this will be implicit in step $\mathrm{b}^{\prime}$ which of course comes after step p.

65 The use of $\dot{\varepsilon} \pi \dot{\imath}$ in this sense is standard.

66 There are several examples (not referring to hyperbolas) in Euclid, Elem.1. 
Next, the introduction of point $P$ early in the proof is explained by the need to 'complet[e] the argument that the parabola contains the hyperbola' [80]. The argument to be 'completed', while necessary of course, is in fact not even sketched in the proof. Point $P$ on the hyperbola beyond $K$ is instead explicitly used in the second part of the proof, and its introduction appears thus motivated by this very requirement: the key point is step $\mathrm{b}^{\prime}$, whose stipulation is eventually equivalent, as Eutocius will explain later [Heiberg 1910-1915, $3.148 .7-18]$, to the $B \zeta A$-solid's being set equal to the $B \Sigma A$-solid. Netz aims instead to show that step p is originally Archimedean, in order to corroborate his thesis that Eutocius 'simply added an adaptation of the proof to the case that is not explicitly covered by the first part' [81], and, by implication, that he did not touch the rest of the proof where the crucial feature (namely, the epi phrase) is located. On the contrary, Netz' analysis itself supports the view that

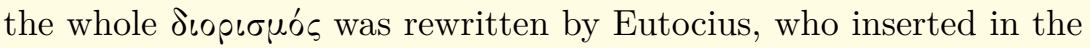
first part constructions of certain objects which were only of use in the second part. The fact that $P$ is inserted in a strict alphabetic sequence in the first part of the proof, as noted by Netz [79n58], simply confirms this thesis. Further, contrary to what is asserted on page 80 [quoted above], step 23 'therefore the parabola is tangent to the hyperbola at $K$ ' [Heiberg 1910-1915, 3.144.6-7] is enough to secure that the hyperbola is above, that is, contained in, the parabola, even if its role as such is not made explicit in the proof. Moreover, step p simply cannot give any information about the location of $P$ and, a fortiori about the relative position of the parabola and the hyperbola. ${ }^{67}$ The upper part of the hyperbola is, therefore, totally useless so far as the first part of the proof is concerned; and the problems arising from the absence of any argument showing that the whole hyperbola is contained in the parabola arise from a reworking of the original proof so as to make it fit the second part.

Finally, the whole 'phantom parabola' argument relies on a logic which, I must confess, escapes me. Let us start with the conclusion. After recalling that "[t]he way to make sense of the location of Step

67 The problem was recognized and discussed to some extent in Netz 1999b, 39 , even though on page 30 of that paper one finds just the assertion quoted above from page 80 of the book under review. Of course, the analysis of $1999 \mathrm{~b}$, 39, which cast strong doubts on the assertion of page 30, has disappeared from the book. 
$\mathrm{p}$ is to understand it as a constituent in an argument in which the second part of the proof is redundant,' Netz writes, 'But we already saw, through the verb "imagine", that the second part of the proof was probably written by a different hand to that of Step p' [81]. In the subsequent line the 'probabilities' are declared to 'begin to accumulate' (actually just one has been offered until now), and then the heap reaches certitude in the subsequent line when Netz writes: 'it is time to replace the cumbersome expression "the author of the second part of the proof", by the simpler name "Eutocius".' (This entails, of course, that it was already well established that the author was not Archimedes, exactly what Netz has set out to prove.) If one looks back for discussion of the verb 'imagine', one finds first that it "is used when the object to be "imagined" is not visible in the diagram, either because it is not an object a diagram can represent directly..., or because it simply is not drawn' [79]. ${ }^{68}$ And then, after the remark about the 'free-floating point $P$ indicating the location of the continuation of the hyperbola', one finds the conclusion:

The diagram is different, and actually extends the hyperbola to $P$. It is probable that whoever drew the hyperbola as far as $P$, was not the one who wrote the text of Step p. But notice that without drawing the hyperbola as far as $P$, the second part of the proof is impossible. Therefore the same probable argument seems to show that the second part of the proof could not have been written by the author of Step p. [80]

I cannot see any argument at all here, not even a probable one, except for the totally fictitious distinction between who drew the hyperbola and who wrote step p. Yet, even in this form, the argument is grounded, as we have seen, on a misunderstanding of the text.

The third argument [81-82] is that the second part of the proof begins with the $\dot{\alpha} \lambda \lambda \dot{\alpha} \delta \dot{\gamma}$ at Heiberg 1910-1915, 3.144.31,

68 These are very basic facts about Greek mathematical style; but a reference is nonetheless provided to Netz 1999a, chapter 1, where allegedly the author had shown that 'imagination..., an established operation in Greek mathematics... often has a precise signification' [79]. The 'imagination' is simply the technical use of the verb voعì. If this is not playing with words! 
an expression which is common in Greek discursive prose but is very rare in the special discourse of Greek mathematical proofs. It is used only once in the Archimedean corpus (of about 100,000 words). For Eutocius, the transition into a formulation that he considered non-Archimedean was sufficient to mark off the remaining text. [82]

This is no argument. To assert that a phrase is 'very rare', one has to produce data. The figure of 100,000 words is there to impress the reader and cannot at all be considered relevant from a statistical point of view. ${ }^{69}$ The reasons why Eutocius considered the formulation with $\dot{\alpha} \lambda \lambda \dot{\alpha} \delta \dot{\eta}$ as non-Archimedean will of course remain a mystery. Notice, moreover, that here Netz keeps silent about the explanation of an editorial choice of his, related to the present issue and made just at the beginning of his translation of Eutocius' remarks to the second

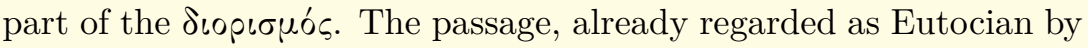
Heiberg, begins at Heiberg 1910-1915, 3.148.1 with é $\pi \iota \sigma \tau \tilde{\eta} \sigma \alpha \iota \delta \dot{\eta}$ ('now one must understand'). This is the reading of the manuscripts; but Heiberg corrects $\delta \dot{\eta}$ to $\delta \varepsilon$. Netz' choice to follow the manuscripts is motivated by the fact that ' $\delta \dot{\eta}$ is a more natural connector inside a stretch of discourse, whereas $\delta \varepsilon$ is a more natural connector at the beginning of a new stretch of discourse' [93n70] — which serves to make his proposal of an early beginning of Eutocius' addition more plausible. ${ }^{70}$ My personal experience is that the contrary is true $;^{71}$ but more important is that a claim like the above must be supported by data, and that it obviously clashes with the just mentioned contention that $\dot{\alpha} \lambda \lambda \dot{\alpha} \delta \dot{\eta}$ at 3.144 .31 opens the Eutocian addition. Moreover, William of Moerbeke's translation has autem in its translation of the line at 3.148 .1 , a canonical, even if not exclusive, way of translating $\delta \varepsilon^{.}{ }^{72}$ $\dot{\alpha} \lambda \lambda \dot{\alpha} \delta \dot{\eta}$ is rendered as at vero, while the only occurrence of autem

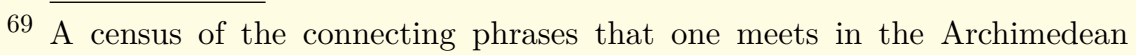
corpus and their relative frequencies would have been much to the point. The occurrence of $\dot{\alpha} \lambda \lambda \dot{\alpha} \delta \dot{\eta}$ is in De sph. et cyl.1.11 [Heiberg 1910-1915, 1.42.23].

${ }^{70}$ Netz takes his proposal as an acquired fact and employs it as a supporting argument for his choice to follow the manuscripts.

${ }^{71}$ It is enough to recall the position of the clause introduced by $\delta \varepsilon$ inside $\mu \varepsilon^{\prime}$... $\delta e^{2} \ldots$

72 Clagett 1976, 41rG, 262. Netz asserts that $\delta \varepsilon \dot{\varepsilon}$ 'may have also been read by the Latin translator' [93n70]. The 'may' deserved a short discussion. 
as a translation of $\delta \eta^{\prime}$ is marked as doubtful even by Clagett, and is very likely William's mistake. ${ }^{73}$ Thus, it is most likely that one has

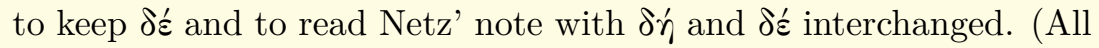
of this supports his proposal for the new location of the beginning of the Eutocian addition, of course.)

The fourth argument [82-83] focuses on the absence of 'scholiastic material' (mainly, exact references to Apollonius' Conica) in the second part of the proof. Netz should have discussed and refuted Decorps-Foulquier's well-founded remark [2000, 82n92] that the presence of similar material in other parts of the proof is the result of a post-Eutocian intervention.

The last argument [83-85] comes from the use in the second part of the proof of primed and uncommon letters of the Greek alphabet to denote points. Netz takes them to be numerals: uncommon letters such as $\zeta, \rho$ already are numerals; common letters become numerals when primed - this usage is very early. The reason for this, according to Netz, is that 'objects labeled by numerals are thereby strongly marked.' More simply and more plausibly, the reason is that the author had exhausted the alphabet at that point of the proof. ${ }^{74}$ Anyone, Archimedes' included, ${ }^{75}$ would have used new symbols when arriving at $\Omega$, most probably primed letters or uncommon letters. ${ }^{76}$

Even with the above drawbacks, the conclusion of the discussion should not just be that Eutocius 'simply added an adaptation of the proof to the case that is not explicitly covered by the first part' [81]. Rather, it has to be that Eutocius reshaped the whole proof in order

73 Clagett 1976, 36vB, 238: cf. Heiberg 1910-1915, 3.56.10. Clagett's reservations $[1976,645,661]$ are expressed in the indices.

74 Netz [83] asserts that 'it is not completely clear whether we should read in our text $\lambda$ or $\Gamma^{\prime}$.' Nothing hangs on it, and I have followed Heiberg's $\Gamma^{\prime}$. In Netz 2004, 328, the claim is sharper: 'I think I might see a $\lambda$ where Heiberg (whom I follow) prints a $\Gamma^{\prime}$.' In fact, $\Gamma^{\prime}$ is Heiberg's emendation: he too read $\lambda$ in the manuscripts, as he says on Heiberg 1910-1915, 3.147 in apparatu (the apparatus in Heiberg 1910-1915 is very often placed on the right-hand page).

75 Netz is aware of this, but suggests that finishing the first part of the proof with all letters of the alphabet employed 'probably was Archimedes' intention' [84n61]. But why 'probably' and to what purpose?

76 There are several examples in the Archimedean corpus, and a further instance occurs in Euclid, Elem.13.16. 
to make it fit the addition of the second part. Eutocius was unable or simply unwilling to write the second part of the proof in a way that was independent from the first one. The best he could do was to make the fictitious chance point $\varsigma$ on $A E$ depend on the original chance point $\Sigma$ on $E B$. Thus, by virtue of the very constraints of the proof Eutocius was proposing, points $\zeta$ and $\Sigma$ are subordinate the one to the other, a fact that entails problems of generality, since $\zeta$ is not in fact a true chance point. Eutocius tried to cope with these

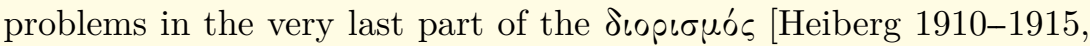
3.148.18-27], where Netz sees the explicit concept of a functional relation. But Eutocius only remarks that, once a suitable parabola (that is, the phantom parabola) is drawn, both $\varsigma$ and $\Sigma$ are obtained by dropping perpendiculars to the main line $A B$ from the points where the parabola intersects the hyperbola: the intersection point

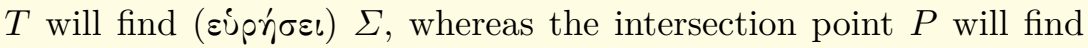
5. To quote Netz again, Eutocius is original in two ways: 'First, he describes the systematic relation holding in the line: the symmetry around the point $E$. Second, he has an explicit concept of a functional relation between mathematical objects' [94], that is, between the points of intersection and the points on the main line. ${ }^{77} \mathrm{~A}$ clue to the efforts Eutocius had to make in proposing such a concept are found in the use of the non-technical verb sipioxeเv [94] - and the discussion ends there!

The apodeictic statement just quoted is simply unfounded. First, as for Eutocius' describing symmetrical configurations around point $E$, no one acquainted with Apollonius' De sectione rationis, for instance, will see any originality in it. But there is a more serious

By composition of the two functional relations just cited (orthogonal projections) and of the one deriving from the fact that $T$ and $P$ are on the same parabola, Netz might even have extended his remark to stating a direct functional relation between $\Sigma$ and $\zeta$. I wonder why Netz did not make the connection explicit, even if hints of it can be found on page 94 . In its stead, we find a very aphoristic conclusion of the whole argument: 'Eutocius' conic section is an arena for equalities between points: it is thus, we may say, a sum of points, defined quantitatively. Thus it has become akin to the conic section of analytic geometry' [95]. What is 'an arena for equalities between points'? What is the $\sigma \dot{u} \mu \pi \tau \omega \mu \alpha$ of a conic section if not a quantitative definition of it? What has analytic geometry to do here? 
problem: the text does not support Netz' interpretation, ${ }^{78}$ to which the concept of a functional relation is eventually reduced [94].

In fact, Eutocius introduces the suitable parabola in the following way. He asserts first that one can take any of the two points solving the problem, either the one between $E$ and $B$ or the one between $E$ and $A$. He then says that if one wants to take the point between $E$ and $B$, then,

as has been said, if the parabola through the points $H, T$ is drawn, cutting the hyperbola at two points, the one closer to $H$, namely, to the axis of the parabola, will find the $<$ point $>$ between $E, B$, as here $T$ finds $\Sigma$, whereas the one farther off the $<$ point $>$ between $E, A$, as here $P$ finds 5 . [Heiberg 19101915, 3.148.22-27: cf. Netz 93-94]

But $T$ is already on the hyperbola [steps $\mathrm{r}$ and s: Heiberg 19101915, 3.144.9-11]! Hence, an independently conceived parabola is not drawn that determines both points of intersection on a par: one of those points is instead needed in order to draw the parabola itself. There is no symmetry at all here. We must conclude that Eutocius did not describe any symmetry around $E$, and a fortiori that he was unable to assess the problems of generality raised by his proof. What could possibly have driven Eutocius to such a lapse I am unable to say; but Netz was perhaps misled by the fact that, in his diagram [71], the phantom parabola does not pass through $T$, as it should do and as it is made to pass in Heiberg's first diagram [Heiberg 1910$1915,3.143] .{ }^{79}$

The epi phrase A by-product of the above analysis is that it would be inappropriate to ascribe the introduction of the crucial epi phrase to Archimedes rather than to Eutocius. The argument offered in support of the claim that the epi phrase was originally Archimedean (the 'explanation' in section 2.2 [see 72-76] has been discussed above) is as follows:

78 But almost surely the text is corrupt and does not correspond to what Eutocius wrote. As Netz remarks [93n76], the entire sentence at 3.148.2127 is introduced by a $\mu \varepsilon^{\prime} \nu$ that finds no correlative $\delta \varepsilon$. Netz ignores the $\mu \varepsilon^{\prime} \nu$ in his translation.

79 There is no information on this feature in the book under review or in Netz 1999b, 2004. 
As explained in section 2.2 above, the source used directly by Eutocius was probably very close indeed to an original Archimedean text, and while Eutocius had certainly transformed this source in several ways, he would have had no motivation for introducing the epi locution (a suitably elliptic prism-based locution would be easily understood by Eutocius, and would not have been more cumbersome than the epi locution). I add that we have the epi locution used repeatedly in Archimedes' Sphere and Cylinder II, the alternative proof to proposition 8 (the penultimate proposition of that book). I personally believe that this alternative proof is by Archimedes himself (it is radically original in many ways, which may explain why Archimedes would have been interested in offering such an alternative proof in addition to a more 'standard' proof - while it is difficult to see who else was capable of and interested in producing such a proof, only to leave it as a gloss in the text of Archimedes!). At any rate, the expression was certainly used in this geometrical context, if not by Archimedes himself, then by some other highly competent Greek mathematician. [103]

As should be clear to everyone, this is no argument at all. It is a good approximation of a circular argument; and it even employs the historians' ultimate resource, the principle of sufficient reason. ${ }^{80}$ The connection between the last and the penultimate sentence is ineffable. What is worse, it omits any mention of parallel passages in later authors (some of the passages will be mentioned some 15 pages later, when the conclusion of the above 'argument' has long been taken for granted), and neglects any obligation to supply precise references to Archimedes' idiosyncrasies as a writer, and so forth. In a word, what is missing is the honest and low-flying apparatus of standard scholarship; in its stead we find an expression of personal belief.

Other assertions in the section are equally questionable. First, the discussion leading to the conclusion that the epi phrase must be read as $A$ (epi $B)$, namely, that it 'is not a single object, but is a composite clause, with a noun - the figure - modified by the adverbial expression "epi line", [106], is grounded on an unsatisfactory

80 This is an argument of the kind sharply criticized in Netz 2002b. 
linguistic argument. It relies on the position of the copula in a statement of equalities of ratios contained in De sph. et cyl. 2.8 aliter: the copula is inside the antecedent of the second ratio, placed exactly between $A$ and epi in the above formula. ${ }^{81}$ Netz claims that ' $[\mathrm{t}]$ he most natural position for this copula in Greek is immediately following the first object of the second part' [106]. But it is one thing to assert that the position is the 'most natural' and another that it is 'the only possible'. In the first case, this is no argument, since if there are exceptions to the rule, the present occurrence might well be one of them. In the second case, the burden falls on Netz to produce some evidence in which such usage is corrected or criticized.

Second, the discussion of associativity is unsatisfactory. We are informed at the beginning of the discussion whose conclusion is that the epi phrase must be read as $A$ (epi $B$ ) that 'the following [discussion] may hold for the arithmetical case as well, but my evidence derives from the geometrical case' [105]. But when associativity is introduced, it is stated that "[i]n both the geometrical and the arithmetical cases, the question cannot even be raised, whether epi is associative or not' [106]. The first sentence quoted is amazing: had Netz no time to check the arithmetical case? And when he wrote the second sentence, did his sample get enlarged without notice? Apart from this, the question of associativity of epi in arithmetical cases can, of course, be raised meaningfully, at least to the same extent that the question of commutativity of epi can [see 104].

Third, a problem of method. On pages 104-106, given the fact that some expressions are unattested, Netz infers the actual impossibility of their having been produced by Greek mathematicians. But, in truth, no such inference is warranted from the absence of expressions like ' $A$ epi $B$ epi $C$ ' or 'line epi figure'. Even if Netz recasts his case with greater care, his discussion of commutativity and associativity appear to rely more on an impossibility argument than on actual evidence. That such an approach is untenable has been shown by Netz himself [2002b].

Fourth, in this and in the subsequent section, it is stated that the epi phrase is exported solely from arithmetical contexts:

we never have an expression of the form... Line epi line. [104]

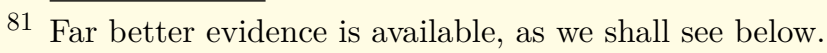


[t]he remarkable thing is that [Archimedes] chose to import an expression from the domain of arithmetical calculations; we would have expected him to import from a nearer domain. [114]

In fact, perpendiculars are canonically said to be drawn epi a straight line or a plane, and they have exactly the function required in the Eutocian epi phrase. It is absurd to dismiss this fact with the following, rather uncorrelated, argument:

the preposition epi does not have the function required. It does not serve as a static description of the three-dimensional object resulting from the plane and the line; rather, it serves dynamically, to lead the act of drawing. [101 $]^{82}$

Fifth, the absence of an expression for a solid such as 'the prism having the area $A$ as base, and the line $B$ as height' instead of the epi phrase is tentatively explained in terms of 'the territorial imperative' of another expression [111]. ${ }^{83}$ I cannot attach any sense to this claim, the author's reference to Netz 1999a notwithstanding.

What is striking in the discussion of the epi phrase are several and conspicuous omissions. These omissions are of two sorts: the first concerns evidence from Hero's works and the second, the presentation of Archimedes' solution.

References to the epi phrase in Hero are limited to a minor occurrence in the preface to Metr. 2 [Schöne 1903, 94.29] ${ }^{84}$ This passage is of a calculative nature and the multiplicative connotation of the epi phrase is plain [114]. But Netz had at his disposal also Metr.1.79 [Schöne 1903, 18.8-11, 22.15-19, 24.10-13, 26.13-22]..$^{85}$ The first and third passages are also calculative and refer explicitly to numbers. But 1.8 is definitely a geometrical proof and appears to contradict

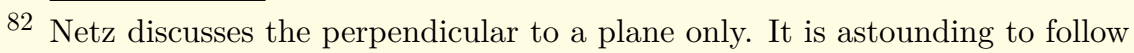
him as he tells us what the Greeks really had in their minds.

83 On the very top of page 110 , there is a misprint which makes the argument difficult to follow: the formula marked $*(30)$ should be marked $*(28)$. Moreover, the formula has a line that should not belong to it. In general, the book would have benefited from a further editing.

${ }^{84}$ Incidentally, the description of the generation of certain solids in this very preface appears to be a good geometrical translation of the epi operation.

85 See also Metr. 3.4 [Schöne 1903, 148.16-25], where one finds both a metrical and a geometrical connotation of the epi phrase. 
at least two statements in this and the preceding sections. The first is that, "[t] he reason Hero allows himself such a language [scil. multiplying an area epi a line] is clear, namely, he simply chooses to ignore the phenomenon of irrationality' [110]. This is false in view of the very claim by Hero that some of his methods are able to cope with 'non expressible' lines [Schöne 1903, 26.3], and of the fact that the triangle in 1.9, for example, is expressly chosen to have the area and hence the height irrational. The second is that "[i]n fact, this $e p i$ is never used in any other context besides "figure epi line"' [104]. In Metr. 1.8, one repeatedly finds 'figure epi figure'. What is more, Pappus refers to 'predecessors who express nothing at all coherent when they say the $<$ rectangle $>$ contained by these $<$ lines $>$ ep $i$ the square on this $<$ line $>$ or epi the <rectangle contained $>$ by these $<$ lines $>{ }^{\prime}{ }^{86}$ Sure, the sentence quoted from page 104 appears to refer to the occurrences in Archimedes and Eutocius. But the whole section is intended to state properties of the epi phrase which are valid in general, as its title 'Is the expression completely algebraic?' [104] shows. ${ }^{87}$ As for the title itself, the expression could not be completely algebraic even in the case 'number epi number': this is not algebra, it is arithmetic.

The translation of Archimedes' analysis in section 1.3 ends with three suspension dots. The omitted text is left uncommented by Netz and may be divided into two parts. The first part [Heiberg 1910-1915, 3.134.13-29] concludes, after a series of standard steps concerning some basic properties of conics, that a certain point $K$ is given. Here is the text of the second part [Heiberg 1910-1915, 3.134.29-136.13]; the translation is taken from Netz [2004, 320] without modifications, apart from omitting his numbering of the deductive steps:

Cf. Pappus, Collectio 7.39 [Jones 1986, 123.8-14 = Hultsch 1876-1878, 680. 15-19]. This crucial, and indisputably geometrical, remark by Pappus serves Netz not as a testimony that the epi phrase was used well before Eutocius in the same way as he himself did, but to support the portrait of Pappus as a mathematical Atticist who reacted to the proposal by advocating and practicing a systematic use of compound ratios: 'Pappus is thus a witness to an avenue leading to algebra - not a participant in this movement' [116]. But then, we should not be interested in Pappus but in his 'predecessors'!

87 One would have expected that general properties of the epi phrase be discussed after a presentation of all the evidence, not before. 


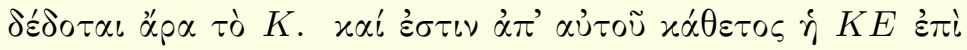

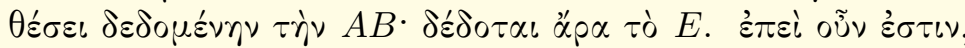

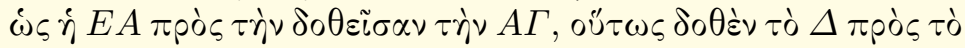

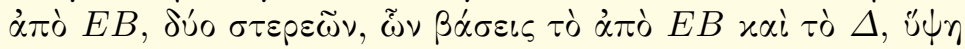

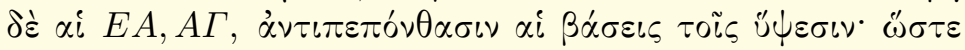

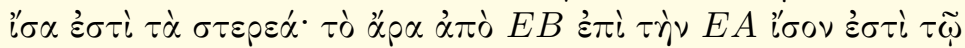

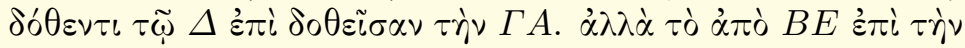

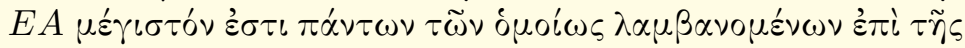

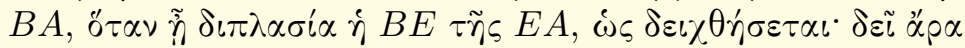

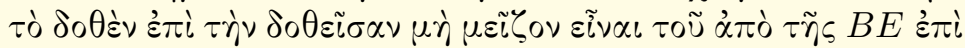
$\tau \dot{\eta} v E A$.

Therefore $K$ is given. And $K E$ is a perpendicular drawn from it to a <line $>$ given in position, <namely $>$ to $A B$; therefore $E$ is given. Now since it is: as $E A$ to the given $<$ line $>A \Gamma$, so the given $<$ area $>\Delta$ to the $<$ square $>$ on $E B$; two solids, whose bases are the $<$ square $>$ on $E B$ and the $<$ area $>\Delta$, and whose heights are $E A, A \Gamma$, have the bases reciprocal to the heights; so the solids are equal; therefore $<$ the solid produced by $>$ the <square $>$ on $E B$, on $E A<$ as the solid's height $>$ is equal to $<$ the solid produced by $>$ the given $<$ area $>\Delta$, on the given $<$ line $>\Gamma A<$ as the solid's height $>$.* But $<$ the solid produced by $>$ the square on $E B^{88}$ on $E A<$ as the solid's height $>$ is the greatest of all the similarly taken $<$ solids $>$ on $B A$, when $B E$ is twice $E A$, as shall be proved; therefore $<$ the solid produced by $>$ the given $<$ area $>$ on the given $<$ line as the solid's height $>$ must be not greater than $<$ the solid produced by $>$ the $<$ square $>$ on $B E$ on $E A<$ as the solid's height $>$.

But why does Netz cut the text off at this point? Yet, the

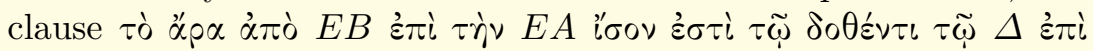
$\delta \circ \theta \varepsilon i \sigma \alpha \nu \tau \dot{\eta} \nu G A$ is the best possible evidence that the epi phrase 'is not a single object': the dative $\tau \widetilde{\varphi} \delta o \theta$ śv $\tau \iota \widetilde{\varphi} \Delta$ makes it clear that the objects to be equated are the base surfaces, not the whole solids. This feature, which is obscured in Netz' translation by his misleading introduction of the phrases <the solid produced by $>$, is argued solely, as we have seen on pp.200-201 above, on the basis

88 For mysterious reasons, the comma in the formula 'square on $A$, on $B$ ' is missing from here on. 
of the single, doubtful example taken from De sph. et cyl.2.8 aliter. Further, the first time the reader meets the epi phrase in Netz' book is at the very beginning of Archimedes' synthesis [16]; whereas in Eutocius' text, the passage reported above comes first, as is natural since it is the end of the analysis. Now, it is not the case that the above passage makes all Netz' elaborations on the epi phrase fall- even if it is inconvenient for Netz to read Eutocius-Archimedes speaking about solids when referring to 'areas epi lines ${ }^{189}$ — but at the very least it deserved a detailed discussion. Why is there none?

Where I have placed an asterisk, one finds the following note in Netz' translation of Archimedes [2004, 320n353]:

The expression 'plane on line' has here a geometrical significance, yet it can also be interpreted as the multiplicative 'on' used in the examples of calculation earlier, where we had 'number on number'. For this ambiguity of meaning, see Netz (forthcoming b).

This is the only place in the whole translation of Eutocius' commentary in Netz 2004 where the epi phrase is mentioned..$^{90}$ One would, therefore, expect that this passage be a major issue for discussion in 'Netz (forthcoming b)' which, as it turns out, is the book currently under review.

Border-crossing: a modest proposal 'As later readers broke down the borders between registers, geometry became algebrized' [120]. I strongly doubt that geometry ever became algebraized in the hands of the Greeks, but we can reasonably ask who broke the borders. As we have seen, Netz completely misconceives Hero's contribution and wrongly rules him out as an early and deliberate border-crosser. Moreover, further uses of the epi phrase by mathematical authors who are undeniably earlier than Eutocius have either been ignored, as we have seen with the passages in Metr.1, or explained away by Netz: the obvious strategy in the latter case was to deem the examples as belonging to minor streams of Greeks mathematics - as if this could be an acceptable historiographical category, given the

89 We find a similar expression, although less explicit, also at the beginning of the synthesis [Heiberg 1910-1915, 3.136.20-28].

90 The issue is very briefly introduced on page 233, within the 'General Comments' to De sph. et cyl. 2.8 aliter. 
extant evidence. Actually, their obvious relevance to the problem at issue is not even discussed, and the examples are no more than very quickly surveyed on pages $112-116 .{ }^{91}$ The occurrences of the epi expression in the Eutocian text, instead, have for Netz the virtue of being contained in a lemma which 'is in pure proportion theory: not some unique isolated point in the outskirts of geometry, but at the very hearth of the Euclidean geometrical discourse' [116-117].

But Eutocius' lemma is not in pure proportion theory: it belongs in the rather exotic and very special theory of the composition of ratios, a subject which appears to have been regarded as worthy of some systematization only in post-Hellenistic authors. Eutocius' lemma does, however, involve manipulations of proportions. But if this is Netz' criterion, most of Greek geometry is 'in pure proportion theory'. Actually, in the whole ancient mathematical corpus, there is just one place where general proportion theory is addressed: Euclid, Elem. 5. Thus, proportion theory is by no means 'at the very hearth of the Euclidean geometrical discourse'. Manipulations of proportion are, of course; but this is another matter. Indeed, such confusion between proportion theory and applications of proportions in geometry is one of the pervasive misconceptions in Netz' book.

The analysis itself of Eutocius' lemma is disconcerting. Step 9

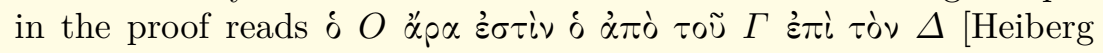
1910-1915, 3.200.4-5] ('therefore $O$ is the <square term $>$ on $\Gamma$, on $\Delta$ ' in Netz' translation [117]). The masculine article $\delta$ instead of the neuter $\tau$ ' permits identifying the result of the operation on the term $\Gamma$ as a 'square term', not merely as a 'square'. This is not the only occurrence in the proof: there are four others in [Heiberg 1910-1915. 3.200.19-24]. Netz comments that there are

two essential ways in which this breaks new ground relative to Classical Greek geometry. First, all objects, regardless of

91 Contrary to what is suggested on page ix, no 'interpretation' is offered of the examples. We find instead on page 115 the remarkable, aphoristic claim: 'The measurement of solids is never defined in mainstream Greek geometry.' What does 'to define' mean here? What is mainstream Greek geometry? Is 'never' relative to the extant evidence or to Greek geometry without qualification? Did Archimedes really not 'measure' solids or is he outside mainstream Greek geometry? Is it necessary to put numbers to a geometrical figure in order to 'measure' it? 
their dimensionality, are considered on a par (everything is a 'magnitude'). Second, objects are directly produced from each other through multiplication $(O$ is the <square term $>$ on $\Gamma$, on $\Delta$ ), and are not just merely related to each other by their geometrical configuration... Things, in the universe of Eutocius' lemma, are defined by the multiplications and equalities that give rise to them... . Step 9-as well as Eutocius' lemma as a whole - firmly belong to the world of algebraic equations. [119]

The first claim of originality is false: ${ }^{92}$ öpos was a technical term in proportion theory since Aristotle, and already in Elem. 5 all objects are considered on a par (everything is a 'magnitude'). ${ }^{93}$ The second claim is vitiated, as we shall presently see, by an unsatisfactory discussion of the textual evidence; and it conveys the strange belief that every proof in Greek mathematics has to refer to some geometrical configuration. But any object in any proof in Greek number theory is 'defined by the multiplications and equalities that give rise to them'.

Now the textual evidence. The critical apparatus in Heiberg's edition (printed in this case on the page facing that of the Greek text) casts doubt on the assertion that the use of the masculine article is 'a remarkable result of the semiotic eclecticism of this text' [117n105]. All of the five occurrences of the masculine article in the proof are recast to neuter pronouns in William of Moerbeke's translation (as well as to neuter articles by modern editors such as Torelli): id quod is consistently used everywhere and the masculine articles before other designations of 'terms' are consistently not translated. ${ }^{94}$

92 In the same page we read, 'Thus the main innovation of Eutocius' textreferring throughout to the object "term"-is determined by Archimedes' [epi] expression.'

93 Much of the alleged novelty of Eutocius' lemma disappears once one realizes that Eutocius simply singles out an abstract step in need of proof, that terms and numbers are regularly represented by line segments, and that products and squares of numbers are canonically expressed in the same terms as their geometrical counterparts [cf., e.g., Elem.9.15] as in any proof in number theory.

94 The weight of William's translation as a testimony is relative, since it appears that the translation of Eutocius' commentaries was made on Valla's now lost codex A. Nevertheless, Heiberg takes it as an independent witness in his apparatus. 
Certainly, it is not unlikely, as Clagett [1976, 43vF-I, 277-278] points out, that William had actually misread the neuter relative pronoun of for the masculine article $\delta$. But we know from a subscription to codex $\mathbf{G}$ that Valla's $\mathbf{A}$ was written using many compendia, and that accents and breathings were not marked [Clagett 1976, 520]. ${ }^{95}$ This makes the choice of $\delta$ versus $\delta$ a matter which a modern editor must make arbitrarily (even if we might have expected to find a neuter article, not a neuter pronoun in the expressions at issue). None of this makes Netz' interpretation impossible. But it does suggest that the passage may have caused troubles to other copyists too, and so serves as a warning against taking the received texts as they have been established by modern editors to be faithful representatives of the originals. On these grounds, no clear-cut inference from such a text should be drawn; and, at any rate, a discussion of the textual matters was mandatory.

Let us return now to the issue of border-crossing. Consider the following proposition, taken from Diophantus' De polygonis numeris. Here 'proportion theory' (in Netz' sense) is undoubtedly at work; border-crossing is patent; and no one would dare to locate Diophantus at an 'isolated point in the outskirts' of Greek mathematics.

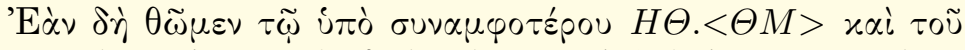

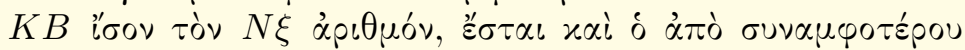

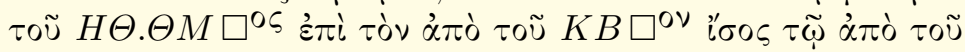
$N \xi \square \varphi .$.

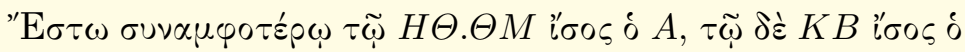

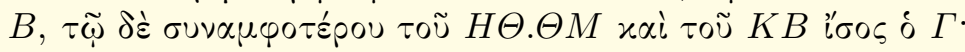

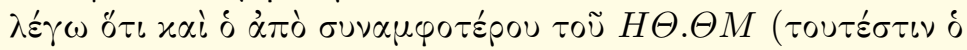

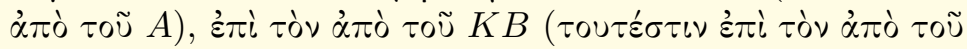
$B)$ í $\sigma . \tau \tilde{\omega} \alpha \pi \dot{\alpha} \tau o \tilde{u} \Gamma$.

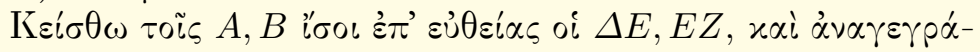

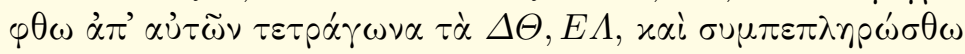

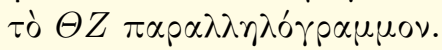

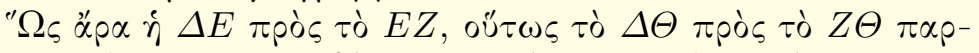

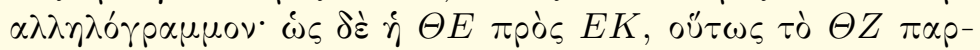

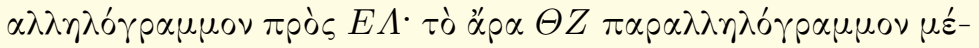

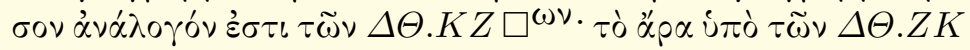

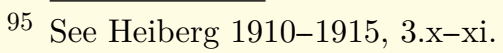




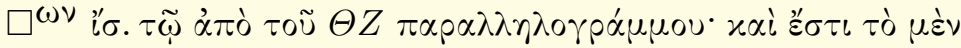

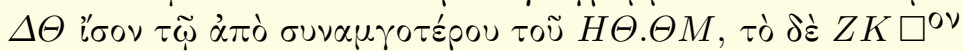

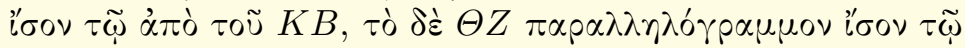

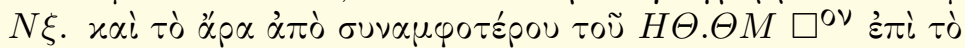

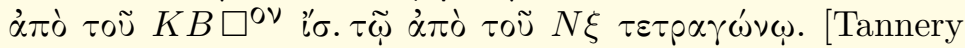
1903-1905, 1.466.1-4 and 1.466.21-468.13] ${ }^{96}$

If we set the number $N \xi$ equal to the $<$ rectangle contained $>$ by $H \Theta \Theta M$ taken together and $K B$, also the square on $H \Theta$ $\Theta M$ taken together epi the square on $K B$ will be equal to the square on $N \xi$...

Let $A$ be equal to $H \Theta \Theta M$ taken together, $B$ be equal to $K B$, $\Gamma$ to the < rectangle contained $>$ by $H \Theta \Theta M$ taken together and $K B$ : I say that, in addition, the <square $>$ on $H \Theta \Theta M$ taken together (i.e., the one on $A$ ) epi the one on $K B$ (i.e., ep $i$ the one on $B$ ) is equal to the one on $\Gamma$.

Let $<$ numbers $>\Delta E, E Z$, equal to $A, B$, be put in a straight $<$ line $>$ and let squares $\Delta \Theta, E \Lambda$ be described on them, and let the parallelogram $\Theta Z$ be completed.

Therefore, as $\Delta E$ is to $E Z$, so $\Delta \Theta$ is to parallelogram $Z \Theta$; and as $\Theta E$ is to $E K$, so parallelogram $\Theta Z$ is to $E \Lambda$. Therefore, the parallelogram $\Theta Z$ is the mean proportional of the squares $\Delta \Theta Z K$. Therefore, the < rectangle contained $>$ by the squares $\Delta \Theta Z K$ is equal to the one on the parallelogram $\Theta Z$; and $\Delta \Theta$ is equal to the <square $>$ on $H \Theta \Theta M$ taken together, the square $Z K$ equal to the one on $K B$, the parallelogram $\Theta Z$ equal to $N \xi$. Therefore, in addition, the square on $H \Theta \Theta M$ taken together epi the square on $K B$ is equal to the square on $N \xi$.

The figure accompanying the text actually displays squares and rectangles; the proof is definitely geometrical. This very aspect should not by any means be dismissed: Diophantus and Hero with him, while not acting as commentators either in the Metrica or in the Arithmetica, obviously broke borders between registers; and they did this well before Eutocius. ${ }^{97}$ Therefore, the deuteronomic character of

96 I keep the format of Tannery's text.

97 Recall, moreover, that al-Bīrūni [Suter 1910-1911, 39] ascribes the procedure for calculating the area of a triangle proved in Metr. 1.8 to Archimedes, and that there we find expressions such as 'figure epi figure' [see p.203, 
the latter's approach cannot be considered the only force (if there exist any such forces) that could and did drive the historical phenomenon of register-crossing. ${ }^{98}$ An effective and, I would say, prior contribution came also from the 'metric tradition', which Netz regards as a minor, segregated stream of Greek mathematics, thereby greatly undervaluing it as an important engine of change.

A less tendentious appraisal of the sources suggests instead a trajectory of the epi phrase that coincides with the mainstream Greek mathematics of the post-Hellenistic period: ${ }^{99}$ Hero $\rightarrow$ Ptolemy $\rightarrow$ Diophantus $\rightarrow$ Pappus $\rightarrow$ other commentators $\rightarrow$ Eutocius. The sources also suggest that the Hero-Diophantus usage of the epi phrase was a matter of course, and that it found a natural application in the composition of ratios, a domain which in its turn was later systematized by Eutocius. ${ }^{100}$ The passages from Diophantus, Pappus, and

above]. Incidentally, one may also wonder why the mixed proportion between magnitudes and numbers introduced in Elem.10, and actually going back at least to Theaetetus, is not considered a proper form of registercrossing.

98 The testimony in Pappus, Coll. 7.39 [see 204n86, above] shows decisively that the expression was also introduced in advanced geometrical research.

99 My use of the term 'mainstream' is, of course, a provocation, since it is a convenient and very often used commodity in Netz' black-and-white world. The concept is, in truth, empty and dangerous: it simply obliterates the selectivity of the textual tradition.

100 Eutocius provides us with two accounts, one in his commentary to De sph. et cyl. 2.4 itself [Heiberg 1910-1915, 3.120.16-126.20], the other in the commentary to Apollonius' Conica [Heiberg 1891-1893, 2.218.3-220.25]. In the first passage, Eutocius mentions Pappus, Theon, one Arcadius, Nicomachus, and one Heronas as preceding authorities on the subject. All of their treatments are deemed as unsatisfactory, on the ground that they relied on inductive proofs only (i.e., proofs based on numerical examples); and Eutocius expressly claims that he is the first to give a satisfactory exposition of the subject. In the second passage, Eutocius asserts that he has provided a third treatment in his 'commentary on the first book of Ptolemy's Syntaxis'. Theon's account is in his commentary to Almagest 1.13 [Rome 1936, 532.1535.9]; and it is likely that the exposition by Pappus to which Eutocius refers was contained in a commentary to Alm. 1 . One further treatment is contained in the so-called Prolegomena to the Almagest, which Knorr [1989, 155-177] identifies as Arcadius'. An inductive exposition constitutes the whole of a short tract by Domninus of Larissa [see Knorr 1989, 201207]. Knorr [1989, 157 and n17] takes 'Heronas in the commentary to the 
other authors entail that the epi phrase was a standard way to refer to complex objects, solids as well as 'multidimensional' figures, when they were considered simply qua magnitudes. Register-crossing was largely practiced well before Eutocius; and the epi phrase in mixed contexts was employed well before him too. The conclusion is simply that Eutocius is merely a late actor in a long-standing tradition.

In this context, I should regard it as more likely, and at least as the safest historiographical stance, to take as a working hypothesis that Eutocius, on looking at the extant De sph. et cyl.2.8 aliter, appropriated the epi phrase from a context well known to him-at a time when a still live tradition supported his choice - in his rewriting of Archimedes' appendix, thereby producing a very effective and concise expression. Netz should adduce more compelling evidence, if he wishes to show that the epi phrase was in the Archimedean original. The occurrences in De sph. et cyl. 2.8 aliter itself are not decisive, as the balance is more contra its authenticity than pro (and, at any rate, Netz should have discussed the issue rather than simply offering his personal beliefs [103: quoted on p. 201, above]). I will just sketch a few of the arguments contra.

Eutocius knows the proposition at the place where we too find it, but Archimedes did not typically write alternative proofs. Apart from the one at issue, the Archimedean corpus contains alternative proofs to De sph. et cyl. 1.7 and to De planorum aequilibriis 1.10 and 13. The former is trivial and clearly spurious; the reasons for which the latter two are unanimously regarded as spurious need not detain us here. The second proof of De sph. et cyl.2.2, although far from trivial, is suspect because it is preceded by a porisma and is inserted into the text in a rather casual way. It is true that our text is the same as that read by Eutocius, but he worked on an Archimedean corpus which had already received conspicuous editorial care. ${ }^{101}$ So,

Arithmetic Introduction' [Heiberg 1910-1915, 3.120.22-23] as referring to an otherwise unknown commentator on Nicomachus' extant tract. But I would suggest a connection with the author of the 'preliminaries to the arithmetic

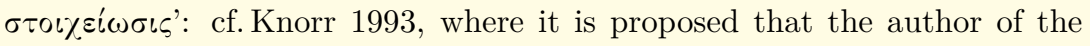
Heronian Def., as well as of the lost Preliminaries, was Diophantus.

Here a careful study of Knorr 1989 is absolutely mandatory. The case of the Dimensio circuli is blatant, but the De sph. et cyl. was also edited: for instance, Eutocius' lemmata in his commentary show that he already read a text deprived of Doric forms. Moreover, I am not convinced that the two 
the occurrence of but two alternative proofs in the whole corpus, both in the same treatise, is certainly grounds for suspicion. More generally, the presence of authorial alternative proofs in advanced works must be argued positively, the presumption being always in favor of their being late additions.

De sph. et cyl. 2.8 aliter is not a full-fledged proof, but a raw reduction, almost a heuristic preliminary to an analysis. ${ }^{102}$ Again, one must argue positively in favor of Archimedes' willingness to present a proof in such a poor state of elaboration, when making it canonical would have required only a minimal work, and against the claim that it was provided by some later scholiast. (It is highly unlikely that the proof in its actual form is the result of large-scale textual corruptions. ${ }^{103}$ ) Moreover, it would be the first instance of a theorematic analysis, a strange beast which was not fashionable form of argument before Hero. ${ }^{104}$ On the other hand, several features of the proof remind us of Pappus' lemmata in Coll.7: the exclusive and straightforward use of a compound ratio in the first part, ${ }^{105}$ the relatively uncon-

mentions by Pappus of an Archimedean $\sigma^{\prime} v \tau \alpha \gamma \mu \alpha$ refer solely to the Dim. circ. and not to some corpus of writings: cf. Pappus, Coll. 5.6 [Hultsch 18761878, 1.314.2] and In Alm. 6.7 [Rome 1931, 254.1].

102 Eutocius supplies the syntheses of the two parts in which the proposition is divided; they are trivial restatements of the analyses framed as searches for preconditions. A nice feature of the text are the two apparently backwardslooking steps [Heiberg 1910-1915, 1.220.16.18] introduced in the majority of the manuscripts by $\delta\llcorner$ เ $\tau \iota$. Heiberg emends them to $\delta \varepsilon \tilde{\iota}$, ö $\tau \iota$ as iotacisms. Regularly introduced by ö $\tau \iota$ are the steps at 1.220.21.25 and 222.3. Contrary to what is stated in Netz 2004, 231, the backward-looking character of the steps is not changed by the emendations.

103 Netz [2004, 230] offers only the usual argument based on the principle of sufficient reason: 'Arguably, no one but the author would dare to introduce such a radical, massive interpolation.' But any alternative proof is a radical, massive interpolation.

104 In Knorr 1986, 356-360, it is vigorously argued that the very concept of theoretical analysis is Pappus'. The first known instances of complete analysis/synthesis of this sort (e.g., the five alternative proofs to 13.1-5 in the Greek tradition of the Elements) are arguably due to Hero [see Heiberg 1903, 59; Vitrac 2001, 399-400 and 2004, 30-34, 40].

105 In the Collectio, Pappus offers several alternative proofs that hinge upon repeated application of compound ratios, clearly suggesting that such a systematic exploitation of the method was his own and that he was proud of 
strained language in the repeated backward-looking statements, ${ }^{106}$ and the very presence of many such statements. ${ }^{107}$ It is difficult not to take De sph. et cyl. 2.8 aliter as a scholastic by-product.

\section{Methodological issues}

Statistics One problem with Netz' argumentation is his use of statistics. ${ }^{108}$ If I am not wrong, statistically-based arguments are used on pages 166 and 168-169 only. They serve in comparing certain features of Archimedes' and Khayyām's proofs. Thus, Netz writes:

Another major difference [between the proofs] has to do with the technical tools used to achieve those aims, especially ratios and proportions.... Archimedes' solution has many more proportion statements than Khayyam's. Of Archimedes' 40 steps, 16 assert proportions (40 percent); of Khayyam's 35 steps, only 4 assert proportions (11 percent). Instead of proportions, Khayyam more often asserts equalities, and he asserts 8 equalities in his argument.... Archimedes' 16 proportions compare with 9 or 11 equalities: Khayyam's 8 equalities compare with 4 proportions. [168-169]

it [see, e.g., Coll.7.68, 74-75, 84, 86, 194, 197, 210, 246, 253, 255, 272]. Compound ratios in the Archimedean corpus are found in De conoidibus et sphaeroidibus 10, 23, 24 [Heiberg 1910-1915, 1.304.13,17; 1.364.12,14,24 and $366.7 ; 1.368 .26$ and 370.6 , resp.]: these are all standard references to properties of cones well known from the Elements. De con. et sphaer. 31 [Heiberg 1910-1915, 1.432.1 10], De sph. et cyl. 2.4 [Heiberg 1910-1915, 1.190.4, 8, 15, 17], De corp. fluit. 2.10 [Heiberg 1910-1915, 2.388.13 and 390.2] and of course 2.8 aliter [Heiberg 1910-1915, 1.216.15.24] are of a different character, and the last occurrence in De corp. fluit. states that the compound ratio of $2: 5$ and $5: 1$ is $2: 1$. It is difficult to draw any clear-cut conclusions from such disparate data, but only 2.8 aliter is wholly grounded on a clever application of compound ratios. In the extant Greek text of Apollonius' Conica, compound ratios feature in 25 enunciations; but it is not said that they are all original.

106 Interesting in this respect is the occurrence twice of ö $\iota$ without governing verb at Heiberg 1910-1915, 1.218.3 and 11.

107 Backward-looking statements are a typical mark of editorial intervention: see Vitrac 2001, 41-69.

108 Statistically-based arguments had far greater prominence in Netz 1999a. 
This would be unexceptionable by itself, but we read the following as a conclusion to a number of increasingly generalizing reformulations of the same idea:

Within geometrical properties, Archimedes foregrounds proportions, backgrounds equalities, Khayyam foregrounds equalities, backgrounds proportions.... It is this inverse ordering of foreground and background that makes the proofs so different, which finally makes us feel that Khayyam's proof 'just couldn't be Greek' - that it is, indeed, already algebra. [171] ${ }^{109}$

I will not discuss either the questionable belief that proportions and equalities are 'geometrical properties', or the idea that the complement of what looks like Greek mathematics is algebra-beyond observing that a similar 'statistical assessment' of the occurrences of equalities and proportions in the first four books of the Elements would probably lead us to conclude that they are pure algebra. More seriously, I offer the following arguments against Netz' use of statistical argument.

- The statistical sample is too restricted: some 40 steps are too few for significant analysis; and only one proposition in an entire treatise is being analyzed.

- This notwithstanding, a clear-cut pattern (foregrounding versus backgrounding) is inferred from data that at best suggest only a marked tendency. This raises serious epistemological problems. That there are 16 steps in a certain Archimedean proof which assert proportions is a fact about the text which has come down to us, a text which may or may not be the same as Archimedes' original. But, in any case, this fact should not be used to imply anything about the existence of such a phenomenon as 'foregrounding'. The latter is at best an interpretation-dependent and statistically based factoid. Even worse, such a factoid requires assuming as an explanatory factor the mental state of a long-deceased mathematician. Such a mental state is forever hidden to us and, at any rate, it can hardly be a matter of inquiry for

109 Notice that, if we take for granted that Diocles' original proof is the one in the Arabic text, the proto-algebraist Eutocius changed the text by foregrounding equalities over proportions (contrary to Netz' belief that he did not rework the proof). 
the historian. In the physical sciences, correlations have replaced causal links, and the existence, for example, of a particle, that is, a fact about the real world, is identified with the existence of a peak in suitable energy spectra. This raises very serious epistemological problems which the practicing physicist simply ignores. In the medical sciences, alleged facts inferred from statistical correlations constitute most of the published material. They are regularly disproved by subsequent statistically-based studies. Informed scholars such as historians of science should handle statistics more carefully.

- The argument fails to account for the fact that the two proofs are neither statistically homogeneous nor mathematically homologous, as Netz himself had just shown [166]. Khayyām's proof has 10 steps of preliminary study of cases; Archimedes' has 6 or 3 (3 steps are already part of the solution), very much as the same proof has ' 9 or 11 equalities'. Such disparities already indicate the fallaciousness of Netz' statistical approach.

- Thanks to Elem.6.16, the borderline between proportions and equalities is permeable enough. Moreover, equalities and proportions obtained from one another by means of 6.16 are not uncorrelated occurrences, and their statistical significance is thereby lowered. The same happens, for instance, when an equality is deduced by transitivity from two other equalities. The third equality is not independent from the first two, and its occurrence does not have the same statistical weight. The same holds for proportions obtained from other proportions by the standard modifications (alternation, ex aequali and so forth).

- The 'step' is somewhat arbitrary as a unit of measurement, even if the high frequency of connectives with sharply defined logical meaning in the prose of Greek geometry makes this choice unambiguous in mo1 st cases. Yet, problems may arise with expressions resuming entire chains of steps in a single clause. A case in point is just the 'vice versa' [quoted on p. 184 above] which Netz includes in step 17 of Diocles' proof. It is plain that the 'vice versa' is at least one new step in the proof, so that Netz errs in his reckoning here. But how many steps really are entailed by the 'vice versa'? Just one step or as many steps as there are in the unfolded deductive chain? Similar problems arise in the case of steps that are understood in the text. 
Anachronisms and over-generalizations One surprising feature of Netz' book is the author's polemical stance against the geometrical algebra, in contrast to his unconstrained use of modern conceptions in describing the achievements of ancient mathematicians. Maybe the underlying ideology is that displaying formulas is anathema, ${ }^{110}$ whereas speaking in the natural language of Eutocius as an unaware proto-algebraist is no anachronism. In fact, if there is a disturbing feature in the book, it is the continuous search for stretches of text where the practice of Greek or Arabic mathematicians 'begins to suggest our own modern algebra' [129]. This perspective is ahistorical and teleologically driven. It amounts to reviving a form of the oldfashioned, long-discredited search for precursors, and, most notably, to maintaining that we are entitled to see more or less concealed forms of algebra in the ancient Greek corpus - the very thesis that Unguru showed to be untenable.

A few examples. Archimedes' choice of using the epi phrase is qualified this way:

This choice, more than any other feature of Archimedes' text, points forwards towards a more algebraic understanding of the problem. Its later appropriation by Eutocius, in particular, would make Eutocius' text appear truly algebraic. [98]

As we have seen, Netz' willingness to see germs of later developments in ancient authors extends as far as claiming that '[Eutocius] has an explicit concept of a functional relation between mathematical objects' [94], even if the claim is immediately recast less sharply as 'The sense of a functional relation between points reflects an awareness of [a] symmetry [around the point $E$ ], no more.' The reason given is that Eutocius

is still not completely modern. For instance, while he notes one structural property - namely the symmetry around $E$ he does not note another, namely the monotonic arrangement of the solutions. [94]

110 But the completely algebraic transcription of Diocles' proof in Toomer 1976, 209-212 is described as 'a very valuable discussion' [39n64]. 
The painstakingly detailed analysis of the monotonic arrangement of

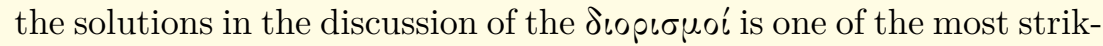
ing features of Apollonius' De sectione rationis. Is Apollonius completely modern? Two pages later the main theme is resumed without qualifications in this way: 'In the case of Diocles' Step 17, Eutocius notices a constant $[s i c]$ functional relationship between two areas of a given diagram' and 'we see Eutocius stumbling, as it were, across the idea of the function.' About the same step, a note to the translation says: 'The author of this passage is aware both of topological considerations, and of a functional relation between variables' [42n78].

Since our proto-algebraist is Eutocius, Archimedes cannot be said to be aware of anything; but he nevertheless still spreads productive seeds:

Besides each [scil. of two conic sections] serving its own specific geometrical function, they also happen to be defined relative to the same lines so that one can -if one wishes todescribe them as functionally interrelated. [28]

and 'he [Archimedes] also happens to produce them in such a way that they can be defined in terms of a functional relation uniting them' [29]. A move which Eutocius will make, of course. All of this is sheer anachronism; and if this is the way in which mathematics is asserted to have a history, I must confess to having a less forwardlooking conception of what history is.

Walter Benjamin once told a beautiful story about the Angel of History: ${ }^{111}$

Es gibt ein Bild von Klee, das Angelus Novus heißt. Ein Engel ist darauf dargestellt, der aussieht, als wäre er im Begriff, sich von etwas zu entfernen, worauf er starrt. Seine Augen sind aufgerissen, sein Mund steht offen und seine Flügel sind ausgespannt. Der Engel der Geschichte muß so aussehen. Er hat das Antlitz der Vergangenheit zugewendet. Wo eine Kette von Begebenheiten vor uns erscheint, da sieht er eine einzige Katastrophe, die unablässig Trümmer auf Trümmer haüft und sie ihm vor die Füße schleudert.

$111 \overline{\mathrm{W} . \text { Benjamin, }}$ Über den Begriff der Geschichte, thesis ix. See Tiedemann and Schweppenhäuser 1974-1989, 1.697. 
A Klee painting named 'Angelus Novus' shows an angel looking as though he is about to move away from something he is fixedly contemplating. His eyes are staring, his mouth is open, his wings are spread. This is how one pictures the angel of history. His face is turned toward the past. Where we perceive a chain of events, he sees one single catastrophe which keeps piling wreckage and hurls it in front of his feet. [Arendt 1969, 257]

The task of the historian is to show that in many instances the Angel is wrong, and that what we perceive as chains of events are really so. But, hélas, there are cases in which such chains remain figments of our perceptive system; and we are left with loose ends scattered in a landscape of rubble. Nor is it permitted to a historian to reconstruct any such chain by taking for granted from the very outset what is its last link: if the Angel itself is looking backwards and bears the vision of such an awful landscape, why should a mere historian, sitting among the ruins, be allowed to interpret the past by looking forwards over the Angel's shoulders? There is nothing behind the Angel.

Overall, in Netz' view, there are general forces that drive historical change, even if his analysis of these forces is grounded on their concrete, material setting such as the practice of working mathematicians. As he sees it, these general forces get instantiated into particular, even minimal, features, from which the general driving principles are nevertheless recoverable. Conversely, the textual evidence demands interpretation in the light of those forces. What is more, in postulating the reality of these general forces, Netz takes certain seeds or elements of change for granted and as necessary, though one can at best argue (as Netz does not) that they they actually are at variance with canonical practices. Thus, he introduces the historiographic category of the 'aura', which enables him to describe the world of Hellenistic mathematics in a way that clashes with the extant evidence, that gives instead obvious prominence to the systematic works of authors like Euclid, Apollonius, and Diophantus. ${ }^{112}$

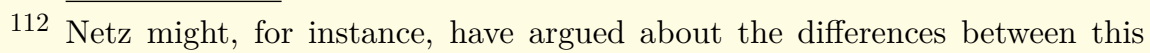
kind of systematics and the one at work in Arabic authors. (It is superfluous to point out how such an emphasis on isolated problems is dependent on Knorr 1986, a book regularly omitted in the bibliography.) To the remark of the prominence of systematic works, Netz replies [10] that the prominence 
Netz' notion of an aura is employed to answer a question which makes sense only from a teleological perspective - and the answer has neither cogency nor historical meaning:

If so, we can explain, historically [sic], why Greek mathematics produced problems, and not equations [this question is meaningless outside a teleological perspective]. Seen inside the context of polemical mathematical practice, it is natural [here is where necessity first appears] that Greek mathematical works should [necessity again] aim [notice the language of intentions applied to inanimate objects] to posses an individual aura, in the sense developed above. Mathematical solutions possessing an aura would naturally [necessity again] have the characteristics we have seen in this chapter: solutions that involve configurations of specific lines that have to be brought into a particular order, everything possessing a mathematical meaning through an individual diagram, created especially for the particular solution. Such solutions strike us as 'problems' in a real geometrical sense, rather than 'equations'. [63]

So, in Greek hands, the particularization in mathematics of the general aim to provide human creations with an aura produced Greek geometry most naturally and necessarily exactly as it was. That is a charming conceit, but it should hardly be termed an explanation, to say nothing of the presumption that it is a historical explanation. Few historians will be persuaded that such general forces exist - at least not on the strength of anything Netz offers - and many will

given to Euclid (he does not mention either Apollonius or Diophantus) is a consequence of a selection made in Late Antiquity, and amounts to a distortion caused by the pedagogical aims of the late editors. But this, while being a commonly held belief of any historian of ancient mathematics, is already an interpretation of the extant evidence and not a fact about Greek mathematics. The other remark,

I believe the work [scil. the Elements] as we know it today may be more systematic than it originally was, due to a Late Ancient and Medieval transformation including, e.g., the addition of proposition numbering, titles such as "definitions" etc. [10]

is so naïve as not to deserve any comment. 
conclude that Netz is describing a world that exists more in his mind than in the extant sources.

Most importantly, Netz' idealistic, fundamentally ahistorical perspective leads him to propose clear-cut over-generalizations in order to capture the essence of whole ages of (mathematical) thought. ${ }^{113}$ The title of the book makes the author's penchant for such overgeneralization clear: a case study is taken to be representative of a whole current of thought and the entire building has a minimal linguistic splinter (the epi phrase) as its foundation. In fact, Netz needs something as the central pier of the bridge which he is going to build from Archimedes to Khayyām. Otherwise the gap between the two would simply have been too wide, thereby supporting Klein's sharp thesis of the great divide. This role is to be played by Eutocius. But we have seen that either Netz' reconstruction is unwarranted or that the role he assigns to Eutocius is greatly exaggerated (and that in its stead a yet largely unexplored net of connections comes to the fore).

It is plain that no historian can do without interpretation. But it is also plain that any inquiry which is not to result in fantasy must at least be conducted in accordance with the shared rules and wellestablished practices of scholarship. It certainly should not proceed by way of an unsatisfactory analysis of the available evidence to grand, unfalsifiable conclusions.

\section{BIBLIOGRAPHY}

Arendt, H. 1969. ed. and trans. Walter Benjamin, Illuminations: Essays and Reflections. New York.

Capasso, M.; Cappelluzzo, M. G.; Concolino Mancini, A.; Falcone, N.; and Longo Auricchio, F. 1976. 'In margine alla vita di Filonide'. Cronache Ercolanesi 6:55-59.

Clagett, M. 1976. Archimedes in the Middle Ages. Volume 2: The Translations from the Greek by William of Moerbeke. Memoirs of the American Philosophical Society 117 (3 parts in 2 tomes). Philadelphia.

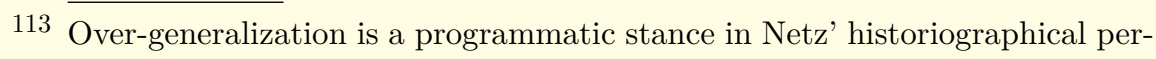
spective: see his discussion on pages 188-189. 
Crönert, W. 1900. 'Der Epikureer Philonides'. Sitzungsberichte der königlichen preussichen Akademie der Wissenschaften zu Berlin 2:942-959.

Decorps-Foulquier, M. 1998. 'Eutocius d'Ascalon éditeur du traité des Coniques d'Apollonios de Pergé et l'exigence de « clarté ». Un exemple des pratiques exégétiques et critiques des héritiers de la science alexandrine'. Pp. 87-101 in G. Argoud, J. Y. Guillaumin edd. Sciences exactes et sciences appliquées à Alexandrie. Saint-Étienne.

1999. 'Sur les figures du traité des Coniques d'Apollonios de Pergé édité par Eutocius d'Ascalon'. Revue d'histoire des mathématiques 5:61-82.

2000. Recherches sur les Coniques d'Apollonios de Pergé et leurs commentateurs grecs. Paris.

Diels, H. 1882. ed. Simplicii in Aristotelis physicorum libros quattuor priores commentaria. Commentaria in Aristotelem Graeca 9. Berlin.

Friedlein, G.1873. ed. Procli Diadochi in primum Euclidis elementorum librum commentarii. Leipzig.

Gallo, I. 1980. 'Vita di Filonide epicureo (PHerc. 1044)'. Pp. 23-166 in I. Gallo ed. Frammenti biografici da papiri II. Rome.

Heath, T. L. 1921. A History of Greek Mathematics. 2 vols. Oxford.

Heiberg, J. L. 1891-1893. ed. Apollonii Pergaei quae graece exstant cum commentariis antiquis. 2 vols. Leipzig.

1903. 'Paralipomena zu Euklid'. Hermes 38:46-74, 161201, 321-356.

1910-1915. ed. Archimedis opera omnia cum commentariis Eutocii. 3 vols. Leipzig.

1912. ed. Heronis Alexandrini opera quae supersunt omnia. Vol. IV: Heronis definitiones cum variis collectionibus, Heronis quae feruntur geometrica. Leipzig.

Hogendijk, J. P. 1986. 'Arabic Traces of Lost Works of Apollonius'. Archive for History of Exact Sciences 35:187-253. 
Høyrup, J. 1997. 'Hero, Ps.-Hero, and Near Eastern Practical Geometry: An Investigation of Metrica, Geometrica, and Other Treatises'. Pp. 67-93 in K. Döring, B. Herzhoff, and G. Wöhrle edd. Antike Naturwissenschaft und ihre Rezeption. vol. 7. Trier.

Hultsch, F.1876-1878. ed. Pappi Alexandrini Collectionis quae supersunt. 3 vols. Berlin.

Jones, A. 1986. ed. Pappus of Alexandria: Book 7 of the Collection. 2 vols. New York/Berlin.

Klein, J. 1968. Greek Mathematical Thought and the Origin of Algebra. Cambridge, MA. (English translation of 'Die griechische Logistik und die Entstehung der Algebra'. Quellen und Studien zur Geschichte der Mathematik, Astronomie, und Physik B3 1934-1936:18-105, 122-235.)

Knorr, W. R. 1982. 'The Hyperbola-Construction in the Conics, Book II: Ancient Variations on a Theorem of Apollonius'. Centaurus 25:253-291.

1986. The Ancient Tradition of Geometric Problems. Boston/Basel.

1989. Textual Studies in Ancient and Medieval Geometry. Boston/Basel.

Kristeller, P. O. 1996. Studies in Renaissance Thought and Letters $I V$. Storia e letteratura: raccolta di studi e testi 193. Roma.

Lloyd, G. E. R. 1996. Adversaries and Authorities. Cambridge.

Netz, R. 1998. 'Deuteronomic Texts: Late Antiquity and the History of Mathematics'. Revue d'histoire des mathématiques 4:261288.

1999a. The Shaping of Deduction in Greek Mathematics. Cambridge.

1999b. 'Archimedes Transformed: The Case of a Result Stating a Maximum for a Cubic Equation'. Archive for History of Exact Sciences 54:1-47.

2002a. 'Omar Khayyām and Archimedes: How does a Geometrical Problem Become a Cubic Equation?' Farhang 14 (3940):221-259. 
Netz, R. 2002b. 'It's not that they couldn't'. Revue d'histoire des mathématiques 8:263-289.

2004. The Works of Archimedes Translated into English, together with Eutocius' Commentaries, with Commentary, and Critical Edition of the Diagrams. Vol. 1: The Two Books On the Sphere and the Cylinder. Cambridge.

Rashed, R. 2000. ed. Dioclès. Pp.1-151 in R. Rashed ed. Les catoptriciens grecs. I: Les miroirs ardents. Paris.

Rome, A.1931. ed. Commentaires de Pappus et de Théon d'Alexandrie sur l'Almageste. Tome I: Pappus d'Alexandrie, Commentaire sur les livres 5 et 6 de l'Almageste. Studi e Testi 54. Rome.

1936. ed. Commentaires de Pappus et de Théon d'Alexandrie sur l'Almageste. Tome II: Théon d'Alexandrie, Commentaire sur les livres 1 et 2 de l'Almageste. Studi e Testi 72. Città del Vaticano.

Schöne, H. 1903. ed. Heronis Alexandrini opera quae supersunt omnia. Vol. III: Rationes dimetiendi et Commentatio dioptrica. Leipzig.

Sidoli, N. 2004. rev. Netz 2004. Aestimatio 1:148-162.

Suter, H. 1910-1911. 'Das Buch der Auffindung der Sehnen im Kreise von Abū'l Raihān Muhammad-al-Bīrūn̄̄'. Bibliotheca Mathematica III Folge 11:11-72.

Tannery, P. 1903-1905. ed. Diophanti Alexandrini opera omnia cum graecis commentariis. 2 vols. Leipzig.

Tiedemann, R. and Schweppenhäuser, H. 1974-1989. ed. Walter Benjamin. Gesammelte Schriften. 7 vols. Frankfurt am Main.

Toomer, G. J. 1976. ed. Diocles: On Burning Mirrors. Berlin/New York.

Unguru, S. 1975-1976. 'On the Need to Rewrite the History of Greek Mathematics'. Archive for History of Exact Sciences 15:67-113.

1979. 'History of Ancient Mathematics: Some Reflections on the State of the Art'. Isis 70:555-565.

Vitrac, B. 2001. trans. and comm. Euclide. Les Éléments. Vol. 4: Livres XI ̀̀ XIII. Paris. 
Vitrac, B. 2002. 'Note textuelle sur un (problème de) lieu géométrique dans les Météorologiques d'Aristote (III.5, 375b16376b22)'. Archive for History of Exact Sciences 56:239-283.

2004. 'À Propos des démonstrations alternatives et autres substitutions de preuves dans les Éléments d'Euclide'. Archive for History of Exact Sciences 59:1-44.

Wilson, N. G. 1996. Scholars of Byzantium. rev. edn. London. 